\title{
Meteorological Tsunami of 19 March 2017 in the Persian Gulf: Observations and Analyses
}

\author{
Mohammad Heidarzadeh, ${ }^{1}$ (D) Jadranka Šepić, ${ }^{2}$ Alexander Rabinovich, ${ }^{3,4}$ Mohammadreza Allahyar, ${ }^{5}$ \\ Ali Soltanpour, ${ }^{6}$ and Farokh Tavakoli ${ }^{7}$
}

\begin{abstract}
On 19 March 2017, destructive tsunami-like waves impacted the northeast shore of the Persian Gulf (PG). The maximum surveyed runup of about $3 \mathrm{~m}$ was observed at Dayyer in southern Iran, where damaging waves inundated the land for a distance of $\sim 1 \mathrm{~km}$ and resulted in the deaths of five people. Because the PG has always been considered safe from extreme oceanic waves, the event was totally unexpected. In this study, we examined sea level data from 12 stations across the PG and a variety of meteorological information, including satellite imagery, high-altitude isohypse maps and high-resolution air pressure records from 47 instruments along the PG. Our results show that the event was very local, with recorded maximum trough-to-crest wave heights of $197 \mathrm{~cm}$ at Dayyer and $234 \mathrm{~cm}$ at Asaluyeh, nearfield cities in Iran located $\sim 80 \mathrm{~km}$ apart. The dominant wave periods were in the range of $15-20 \mathrm{~min}$. At all distant tide gauges, the observed wave heights were $<35 \mathrm{~cm}$. No earthquakes or landslides were evident at the time of the event. On the other hand, atmospheric processes during 18-22 March were very active and 10 distinctive tsunamigenic air pressure disturbances were observed propagating over the PG, suggesting that the event of 19 March 2017 was a "meteorological tsunami". Atmospheric conditions over the PG were highly favourable for the generation of meteotsunamis and very similar to those that caused a chain of strong meteotsunamis in the Mediterranean and Black Sea regions during 23-27 June 2014. Based on the $500 \mathrm{hPa}$ wind, we evaluated that the disturbances had propagation speeds of $21-38 \mathrm{~m} / \mathrm{s}$, with the disturbance at Dayyer having a speed of $\sim 26 \mathrm{~m} / \mathrm{s}$ toward $77^{\circ}$ True. The Froude number, $\mathrm{Fr}$ (estimated as the ratio of the air disturbance speed to the long wave speed), on 19 March 2017 in the Dayyer/Asaluyeh region was close to resonance, $\mathrm{Fr} \sim 0.9$ to 1.1 , which is highly favourable for meteotsunami generation. Our findings indicate that the Dayyer/Asaluyeh area is a "hot spot" that
\end{abstract}

1 Department of Civil and Environmental Engineering, Brunel University London, Uxbridge UB8 3PH, UK. E-mail: mohammad.heidarzadeh@brunel.ac.uk

2 Institute of Oceanography and Fisheries, Split, Croatia.

3 P.P. Shirshov Institute of Oceanology, Russian Academy of Sciences, Moscow, Russia.

4 Institute of Ocean Sciences, Fisheries and Oceans Canada, Sidney, BC, Canada.

5 Port and Maritime Organization, Tehran, Iran.

6 Hydrography and Tidal Analysis Department, National Cartographic Center, Tehran, Iran.

7 Geodetic Department, National Cartographic Center, Tehran, Iran. is highly vulnerable to extreme, weather-induced tsunami-like waves.

Key words: Persian Gulf, meteotsunami, extreme waves, atmospheric waves, tide gauge data, wavelet analysis, remote sensing.

\section{Introduction}

The Persian Gulf (PG) is an extensive inland sea, located between the Arabian Peninsula and Iran, that connects to the Indian Ocean (Gulf of Oman) through the relatively narrow Strait of Hormuz. This is a shallow basin: mean and maximum water depths in the PG are $50 \mathrm{~m}$ and $90 \mathrm{~m}$, respectively (Fig. 1). Unlike the neighbouring Gulf of Oman, which is at risk to hazardous cyclones (cf. Fritz et al. 2010) and damaging tsunamis (e.g. the 1945 Makran tsunami killed 300 people; Heidarzadeh et al. 2008), the Persian Gulf has always been considered as relatively safe. Major storm surges or detectable tsunamis have never been observed in this basin (El Sabh and Murty 1989; Lin and Emanuel 2016). Moreover, there are no documented substantial crustal faults in the Persian Gulf region capable of producing major tsunamigenic earthquakes $(M>7.5)$, while tsunami waves from the Indian Ocean either have not penetrated into the PG or have been strongly attenuated once inside the basin (Rabinovich and Thomson 2007; Ambraseys 2008; Heidarzadeh et al. 2008). As a consequence, the highly destructive tsunami-like waves that impacted the northern shore of the PG on 19 March 2017 were totally unexpected.

Waves associated with the March 2017 event reached a maximum runup height of approximately $3 \mathrm{~m}$ at the area of Dayyer in southern Iran (Fig. 1) 


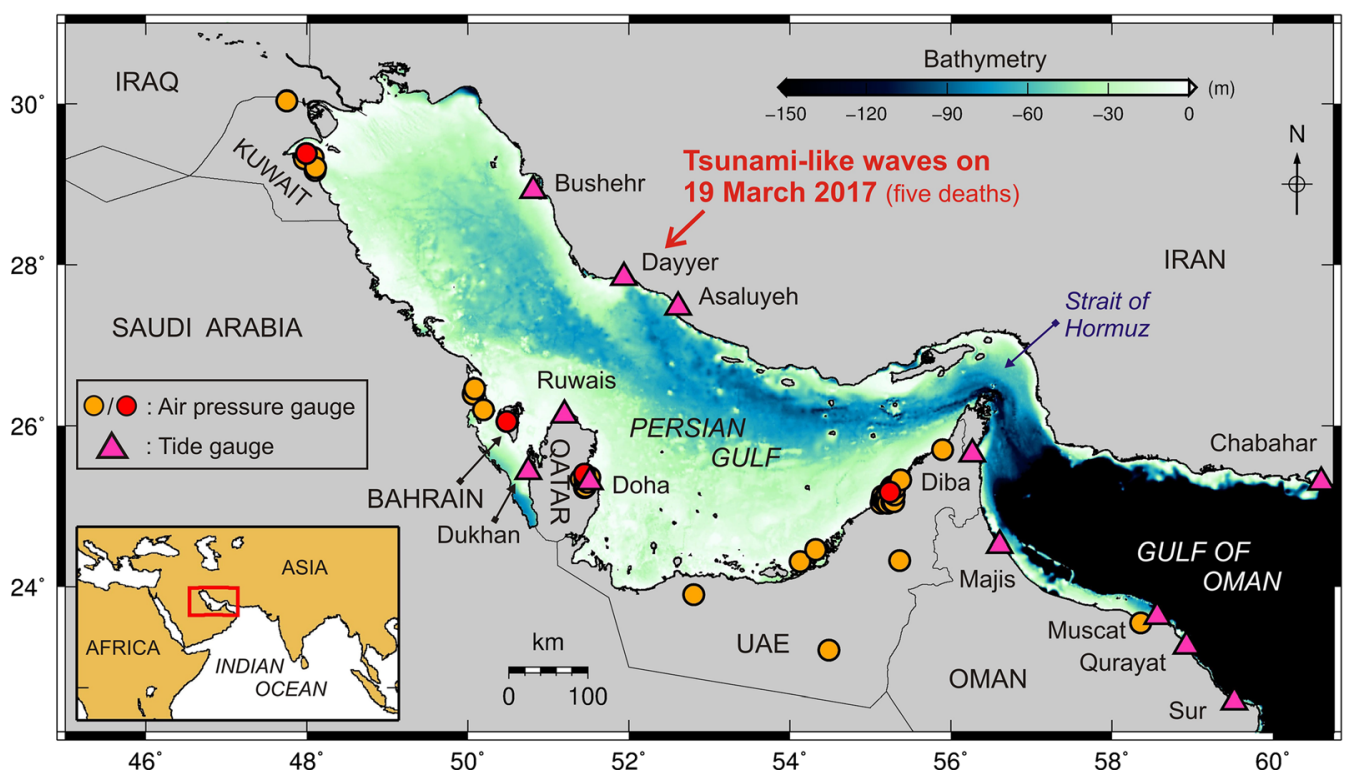

Figure 1

Map showing Dayyer and other regional tide gauges and air pressure stations located within and outside the Persian Gulf. Dayyer was the site of deadly tsunami-like waves on 19 March 2017. Air pressure gauges shown in red are those used for wavelet analysis

and flooded inland for $\sim 1 \mathrm{~km}$, resulting in severe damage and five deaths. Salaree et al. (2018) provided a field survey of the affected coastline $(\sim 40 \mathrm{~km})$ and collected witness reports that enabled them to reconstruct a preliminary picture of the entire event, including estimates of runup and inundation along the coast. The main focus of their study was to identify the physical mechanism responsible for these extreme waves. First, they checked the seismic activity at the time of the event and, because there were no noticeable earthquakes in the area at the time, ruled out a seismic origin for the observed tsunami-like waves. Salaree et al. (2018) then considered the possibility of a submarine landslide in the vicinity of Dayyer. A numerical simulation of possible landslide-generated waves demonstrated that a submarine slide was a highly unlikely cause of the event. Having eliminated all other generation mechanisms, Salaree et al. (2018) concluded that the 2017 wave event at Dayyer had an atmospheric origin, i.e. that the event was a meteorological tsunami.

Meteorological tsunamis ("meteotsunamis") are tsunami-like waves that have the same temporal and spatial scales as ordinary tsunami waves but are generated by atmospheric processes rather than seismic sources or landslides (Rabinovich and Monserrat 1996; Monserrat et al. 2006). Meteotsunamis can affect coastal regions in a destructive way, similar to seismic tsunamis, causing loss of life and severe damage to local infrastructure. Meteotsunamis reported throughout the World Ocean, were either in the form of "harbour meteotsunamis" (multiple harbour seiche oscillations) in harbours/bays with high $Q$-factors ${ }^{1}$ (Monserrat et al. 2006; Rabinovich et al. 2009), or in the form of "beach meteotsunamis" (solitary waves observed near straight beaches). Destructive harbour meteotsunamis have occurred in Ciutadella Harbour in Spain, Vela Luka and Stari Grad bays in Croatia, Nagasaki Bay in Japan, Mazara del Vallo Harbour in Sicily, Italy, and in certain bays in the Great Lakes in North America (Ewing et al. 1954; Hibiya and Kajiura 1982; Šepić et al. 2015, 2018a). A spectacular example of a beach meteotsunami is the 1992 "Daytona Beach event" in Florida, USA (Churchill et al. 1995; Sallenger et al. 1995). Other examples are the 2014 events in Praya

\footnotetext{
${ }^{1}$ Quality $(Q)$ factor is a measure of energy damping in the system: the higher $Q$ is, the slower the energy decays, and the stronger wave amplification is within the harbour (Rabinovich 2009).
} 
de Cassino (Brasil), Panama City (Florida, USA), and Odessa (Ukraine) (Vilibić et al. 2016; Šepić et al. 2015, 2018b).

The crucial factor responsible for the generation of strong meteotsunamis is the need for the speed of an atmospheric disturbance $(U)$ to match the phase speed $(c)$ of the long ocean waves (the so-called "Proudman resonance" condition; Proudman 1929):

$$
U \sim c
$$

where $c=\sqrt{g h}, g$ is the gravity acceleration and $h$ is the water depth. The governing parameter determining the sea level response to the atmospheric forcing is the Froude number, defined as:

$$
F r=\sim U / c .
$$

Resonance occurs when $F r \sim 1.0$ (Vilibić 2008; Šepić et al. 2015). Most often, meteotsunamis are observed on the "windward coasts" (onshore disturbance direction), however they can also be induced on "leeward coasts" (offshore disturbance direction) - the situation caused by reflections from the opposite coast (Ewing et al. 1954), or from the shelf break (Pasquet and Vilibić 2013; Šepić et al. 2018b). The Proudman resonance normally plays the key role in formation of prominent meteotsunamis (Vilibić 2008), but in specific situations of alongshore propagating disturbances, significant meteotsunamis can be generated due to the Greenspan resonance (Munk et al. 1956; Greenspan 1956). Salaree et al. (2018) assumed that favourable conditions for the Proudman resonance existed in the PG on 19 March 2018, and that was the main reason for the extreme tsunami-like waves affecting Dayyer. Based on the results of numerical experiments, Salaree et al. (2018) found that the atmospheric source model provides much better agreement with the results of the field survey than any landslide model. However, their model could not adequately explain the distribution of wave amplitudes along the coast. The lack of atmospheric and sea level data in the area of the event did not allow Salaree et al. (2018) to investigate this problem in detail and to relate the observed destructive surge waves to the specific atmospheric disturbance with their particular propagation parameters.

Our study of the Dayyer event is based on sea level records from 12 stations, including the Dayyer tide gauge (Fig. 1) and comprises statistical, wavelet, and spectral analyses of the corresponding data. In addition, we also examined 47 high-resolution air pressure records from several countries located in this region (Kuwait, Saudi Arabia, Bahrain, Qatar, UAE and Oman) (Fig. 1), and various satellite data. These numerous data enabled us to understand the general atmospheric situation in the PG region and to estimate the propagation characteristics of atmospheric waves at the time of the Dayyer event.

\section{Description of the Event}

On 19 March 2017 at around 8:00 AM local time (4:30 UTC), large waves impacted the northern shore of the PG. According to media reports and field surveys by Salaree et al. (2018), the maximum runup heights near Dayyer (Figs. 1, 2) reached $3 \mathrm{~m}$; the inundated distance was up to $1 \mathrm{~km}$. The waves affected about $40 \mathrm{~km}$ of the coastline, causing five deaths and injuring 20 people. Local authorities reported damage to $\sim 300$ fishing and recreational boats and 85 coastal properties. The event was largely referred to as a tsunami in the Persian media, since its wave heights, periods, inundation patterns and the destructive power resembled typical tsunami waves. Numerous videos recorded bore-like waves attacking the coast; a few images from two of these videos are shown in Fig. 2.

The Dayyer event of 19 March 2017 did not have the character of a "harbour meteotsunami", and affected a long segment $(\sim 40 \mathrm{~km})$ of a fairly straight beach. In fact, this was a classical "beach meteotsunami", similar to the 1992 Daytona Beach and 2014 Odessa events. As discussed by Salaree et al. (2018), the 2017 Dayyer event took place during a calm and cloudy day, preceded by a significant thunderstorm occurring a few hours before the tsunami. This is typical for meteotsunamis in that they commonly are not associated with extreme weather conditions, but rather with relatively calm weather. This was also the situation for the 1992 Daytona Beach, 2014 Odessa and 2014 Praya do Cassino meteotsunamis, as well as for a number of events on the coast of British Columbia (Thomson et al. 2009) and in the Mediterranean Sea (Monserrat et al. 2006). 
(a) Video 1
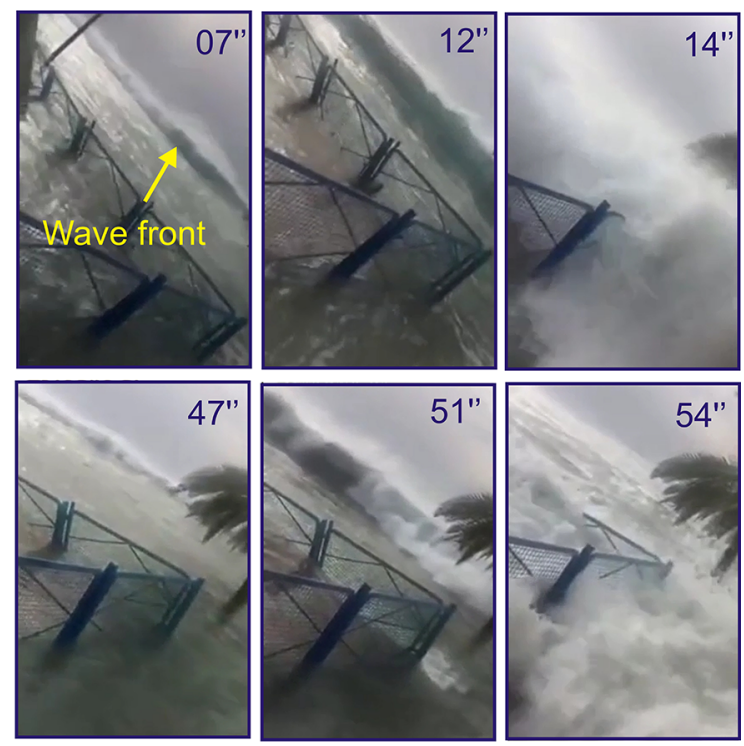

(b) Video 2
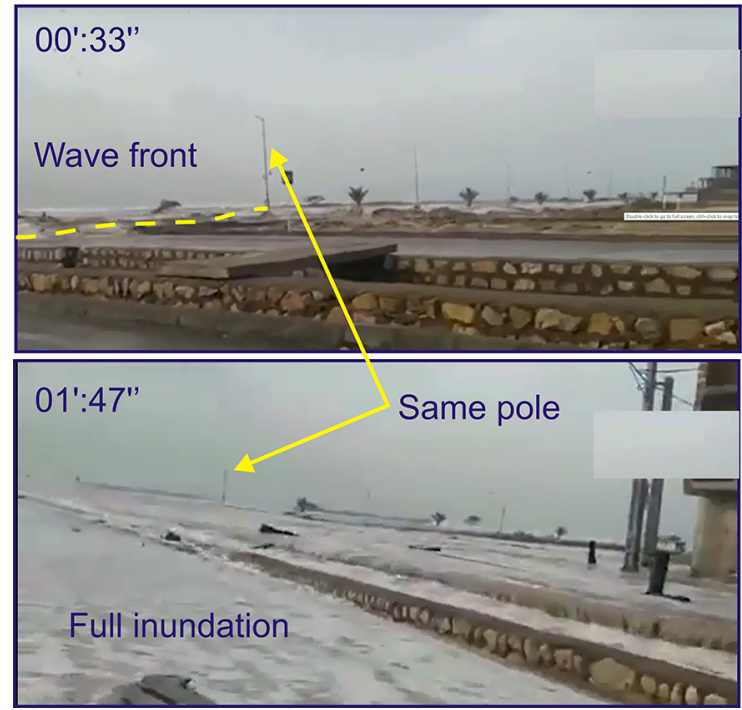

Figure 2

Snapshots of videos showing the inundation of the 19 March 2017 Dayyer tsunami-like waves. The times shown on the corners of the panels are relative to the start of each video. The sources for videos a, b are: http://jamejamonline.ir/nama and http://www. eghtesadonline.com/, respectively

The 2017 Dayyer event is the first known example of recorded destructive waves in the Persian Gulf, which caused severe damage and killed people. The PG is the main hub for worldwide oil supply as giant oil producers (Saudi Arabia, Iran, UAE, Iraq, Qatar, Kuwait and Bahrain, Fig. 1) export most of their oil through this gulf and the Strait of Hormuz. In addition, the PG coasts host some large cities, such as Dubai, Abu Dhabi and Doha (Fig. 1). Therefore, thorough insight into this event is vitally important.

The satellite data analysis revealed a sand storm that was formed in North Africa (in the area of Libya) and propagated over the PG (Fig. 3) around the time of the Dayyer event (18-19 March 2017). It is likely that this sand storm and the air pressure disturbances, that appear to have been responsible for the Dayyer extreme waves, are associated with the same atmospheric system. The entire situation looks comparable to the one observed over the Mediterranean-Black Sea region on 23-27 June 2014, when an atmospheric synoptic pattern ("tumultuous atmosphere"), propagating eastward, supported the generation of numerous intense small-scale atmospheric disturbances, which subsequently resonantly triggered meteotsunamis in coastal areas with $F r \sim 1.0$ (Š́epić et al. 2015). Similar atmospheric disturbances are seen in most of the air pressure records in the PG region (Sect. 5), while local surges and strong seiche oscillations are detected in individual tide gauge records across the region (Qatar, Oman, UAE and Iran), with the extreme waves observed specifically at the area of Dayyer (Sect. 4).

\section{Data and Methodology}

\subsection{Sea Level Data and Analysis}

Sea level data from 12 tide gauges were used in this study (Fig. 1; Table 1). The Dayyer station is located at the centre of the region affected by the devastating waves. The gauge, which is operated by the National Cartographic Center (NCC) of Iran, is based on ultrasonic transducers; sea levels are recorded at 5-min intervals. The instrument was originally deployed for tidal measurements; thus the 5-min sampling interval was quite adequate. However, such a sampling rate is not optimum to measure short-period events, like the destructive waves that occurred on 19 March 2017. Two more Iranian tide gauge records, Asaluyeh and Bushehr, that also had a sampling interval of $5 \mathrm{~min}$, were provided by the Port and Maritime Organization (PSO) of Iran (https:// 

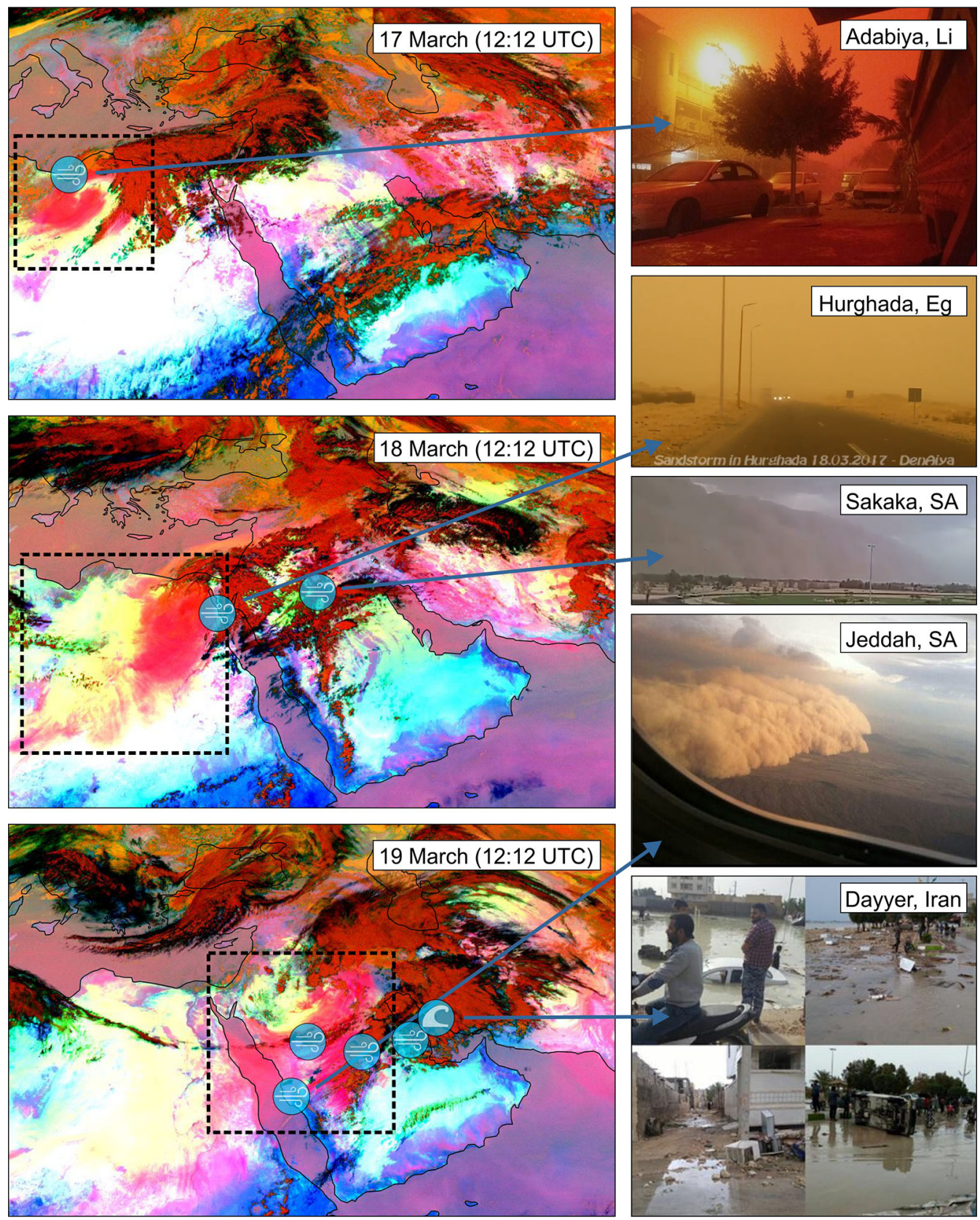

Figure 3

Sequence of satellite images taken over the Middle East during 18-19 March 2017, revealing the development and propagation of a sand storm from Libya, over Egypt and Saudi Arabia, towards the Persian Gulf. The sand storm is represented with purplish colours (within the dashed boxes). Locations of reported sand storm and tsunami events are marked with appropriate symbols, at times closest to event times.

Photos taken during these events are shown in the right column

www.pmo.ir/en/home). The three Qatar records at Ruwais, Doha and Dukhan, all with sampling intervals of $10 \mathrm{~min}$, were supplied by the Hydrographic Unit of the Qatar Ministry of Municipality and
Environment. The data from six tide gauges (from Oman and Chabahr, Iran) with sampling intervals of $1 \mathrm{~min}$ were provided by the Intergovernmental 
Table 1

Information of the tide gauge and wave gauge records analysed in this study

\begin{tabular}{lllllcc}
\hline Station name (country) & Longitude $\left({ }^{\circ} \mathrm{E}\right)$ & Latitude $\left({ }^{\circ} \mathrm{N}\right)$ & Type $^{\mathrm{b}}$ & $\begin{array}{l}\text { Sampling } \\
\text { interval (min) }\end{array}$ & Max wave height $^{\mathrm{a}}(\mathrm{cm})$ & $\begin{array}{c}\text { Visible } \\
\text { period (min) }\end{array}$ \\
\hline Dayyer (Iran) & 51.94 & 27.84 & WG & 5 & 197 & 20 \\
Asaluyeh (Iran) & 52.62 & 27.47 & TG & 5 & 234 & 15 \\
Bushehr (Iran) & 50.82 & 28.92 & TG & 5 & 26 & $30-40$ \\
Ruwais (Qatar) & 51.20 & 26.13 & TG & 10 & 32 & 40 \\
Doha (Qatar) & 51.52 & 25.30 & TG & 10 & 17 & $20-30$ \\
Dukhan (Qatar) & 50.75 & 25.43 & TG & 10 & 30 & $20-30$ \\
Diba (Oman) & 56.27 & 25.65 & TG & 1 & 33 & N/A \\
Majis (Oman) & 56.61 & 24.52 & TG & 1 & 26 & $10-20$ \\
Muscat (Oman) & 58.57 & 23.63 & TG & 1 & 25 & $10-15$ \\
Quaryat (Oman) & 58.93 & 23.26 & TG & 1 & 24 & 5 \\
Sur (Oman) & 59.52 & 22.57 & TG & 1 & 15 & $15-20$ \\
Chabahr (Iran) & 60.60 & 25.30 & TG & 1 & N/A \\
\hline
\end{tabular}

${ }^{\text {a }}$ Trough-to-crest height; ${ }^{b} \mathrm{WG}$ and TG indicate the wave gauge and tide gauge, respectively, "N/A" means "Not Applicable"

Oceanographic Commission (http://www.iocsealevelmonitoring.org/map.php).

Sea level data were de-tided based on the least squares method of harmonic tidal analysis and consequent removing of tides from the original records. Our spectral analysis procedure was similar to that described by Thomson and Emery (2014). To improve the spectral estimates, we used a KaiserBessel (KB) window with half-window overlaps prior the Fourier transform. To examine temporal variations of the observed event in the frequency domain, we used a multiple-filter method, which is based on narrow-band filters with a Gaussian window that isolates a specific centre frequency (cf. Rabinovich and Thomson 2007; Rabinovich et al. 2013). The method is similar to wavelet analysis (Thomson and Emery 2014).

To examine the spectral properties of the tsunamilike oscillations of 19 March 2017, and to compare these properties with those of the background oscillations at the same sites, we separated the records into two parts. The time period preceding the event (approximately 3.5 days) was identified as "normal" and selected for analysis of background signals. For the "tsunami" (event) period following the extreme wave arrivals, we took the time period of $1280 \mathrm{~min}$ $(\sim 21.3 \mathrm{~h})$. The length of the $\mathrm{KB}$ window was chosen to be $640 \mathrm{~min}$, yielding $v=30$ degrees of freedom for background spectra and $v=6$ for the tsunami spectra. The spectral resolution for all spectra was $\Delta f \approx 0.094 \mathrm{cph}$ and the Nyquist frequency $f_{\mathrm{N}} \approx 0.17 \mathrm{cph}$. The main attention was paid to analysing the records at two stations, Dayyer and Asaluyeh, that are located in the affected area and, according to Fig. 4, measured strong tsunami-like oscillations. The results of spectral analysis of these two records are shown in Fig. 6a, b, respectively.

Rabinovich (1997) suggested a method to separate the influences of the topography and the source on the observed tsunami spectrum. The method is based on the assumption that background long waves and tsunami waves approaching the coast, are transformed by the topography in a similar way, i.e. that the topographic transfer function for both types of waves is the same. In that case, if we estimate the ratio of the tsunami to the background spectrum

$$
R(\omega)=S_{\mathrm{tsu}}(\omega) / S_{\mathrm{bg}}(\omega),
$$

where $\omega$ is the angular frequency, we eliminate the influence of topography and obtain a function determined solely by the external forcing. The ratios show not only the spectral structure of the source, but also the frequency diapason of the forcing and the relative amplification of the tsunami signal at various frequencies relative to the background oscillations. The similarity of the computed ratios for different stations normally gives the evidence of the identity of the source (that is why these ratios are also known as the "source functions"). This method was successfully used for a great number of tsunami events (cf. 
Rabinovich 1997; Rabinovich et al. 2013; Zaytsev et al. 2017). Monserrat et al. (1998) and Marcos et al. (2009) demonstrated that this approach is also effective for meteorological tsunamis.

\subsection{Atmospheric Data and Analysis}

To analyse the general synoptic situation over the Middle East during 17-22 March 2017, we used the ERA-Interim reanalysis data with $0.75^{\circ} \times 0.75^{\circ}$ spatial resolution and 6-h time resolution $(00,06,12$ and $18 \mathrm{~h}$ UTC). To investigate atmospheric processes in the affected region in more detail, we downloaded surface atmospheric records from the amateur meteorological network Wunderground (https://www.wunderground. com/wundermap). Although these records did not have the quality control provided by state meteorological organizations, they can be effectively used for scientific research and studies of atmospheric disturbances responsible for meteorological tsunamis (cf. Šepić et al. 2015). Altogether, we found data of satisfactory quality from 47 meteorological stations (Fig. 1). Various variables are measured at these stations, including air temperature, dew point, humidity, wind velocity and gust, precipitation, atmospheric pressure, etc. Since the main drivers of meteotsunamis are air pressure waves and disturbances (cf. Monserrat and Thorpe 1992; Rabinovich and Monserrat 1996; Monserrat et al. 2006), we have focused our attention on atmospheric pressure measurements, which were recorded with samplings of 5-25 min, depending on the station. Prior to the analysis, all pressure series were interpolated to a 5-min time step. Unfortunately, the available Wunderground stations were located on the western and southern coasts of the PG-in Kuwait (6 stations), Saudi Arabia (3), Bahrain (1), Qatar (8), United Arab Emirates (26) and Oman (2) - and none on the eastern or northern PG coasts (e.g. in Iran) (Fig. 1). This means that, sadly, we did not have surface meteorological observations located close to the area affected by the tsunami-like waves of 19 March 2017 and had to use the data from relatively remote stations.

Assuming that the atmospheric pressure disturbance propagates as a plain wave with a constant speed and direction, we can estimate these parameters from atmospheric pressure records by the least squares method (LSM) (cf. Orlić 1980; Thomson et al. 2009). The velocity parameters of the propagating air pressure disturbances were estimated in two variants: (1) based on all stations which measured the corresponding disturbance; and (2) based only on stations located more than $5 \mathrm{~km}$ apart from each other. Further on, it was reliably shown that tsunamigenic air pressure disturbances propagate with the speed and direction of a higher altitude/level guiding wind (cf. Monserrat and Thorpe 1992; Šepić et al. 2009; Thomson et al. 2009). In fact, these disturbances are often a surface manifestation of high-altitude processes spanning up to the level of $\sim 500-\mathrm{hPa}$ (approximately $5500 \mathrm{~m}$ above the ground) (Monserrat and Thorpe 1996). Since measurements at these levels are sparse, we extracted $500-\mathrm{hPa}$ wind speed and direction from the ERAInterim reanalysis data set, available at 6-h intervals with a spatial resolution of $0.75^{\circ} \times 0.75^{\circ}$ and used these data to approximate the velocity parameters of propagating air pressure disturbances.

\subsection{Satellite Data and Analysis}

We have also analysed satellite images of the Persian Gulf and adjacent regions taken with the MVIRI instrument of the EUMETSAT Meteosat7 satellite (https://www.eumetsat.int/website/home/ Satellites/CurrentSatellites/Meteosat/index.html).

Satellite images were processed to show a composite of the following RGB channels: 05-06; 04-09; 03-01. This composite is regularly used to show convective activity during daylight hours, with convective clouds depicted with yellowish colours (Kerkmann 2005).

\section{Tsunami Waveforms Analysis and Physical Properties of the Observed Sea Waves}

\subsection{Parameters of the Observed Sea Level Records}

The Dayyer wave gauge, which is the closest station to the area impacted by the tsunami, recorded a maximum trough-to-crest wave amplitude of $197 \mathrm{~cm}$ at 08:10 AM local time (04:40 UTC) on 19 March 2017 (Fig. 4), consistent with the timing of the event according to the media reports. The actual wave height at Dayyer appears to be higher than $197 \mathrm{~cm}$, 
but was attenuated due to the 5-min sampling interval of the recorded data, which is too long for shortperiod processes. At Asaluyeh, located approximately $80 \mathrm{~km}$ to the $\mathrm{SE}$ from Dayyer, the maximum recorded tide gauge wave height was $234 \mathrm{~cm}$, which also was probably attenuated by the 5-min sampling. The ratio between tide gauge recorded wave heights $\left(H_{\mathrm{tg}}\right)$ and field survey estimated tsunami runups $\left(H_{\mathrm{ru}}\right)$ is one of the most important and difficult questions in the tsunami observations. It appears that this ratio depends on a number of factors and, first of all, on particular topographic properties of the region. Nevertheless, if we use an empirical coefficient $H_{\text {ru }} /$ $H_{\text {tg }} \approx 1.4$, proposed by Soloviev (1978), we find very good agreement between runup estimates from the field survey of Salaree et al. (2018), $3.0 \mathrm{~m}$, and tide gauge measurements at Dayyer and Asaluyeh.

Other regional tide gauges, both inside and outside the PG, at the time of the Dayyer event registered wave heights in the range of $5-32 \mathrm{~cm}$ (Figs. 4, 5). Three Qatar tide gauges, located on the southern coast of the PG opposite Dayyer, recorded maximum wave heights of $17-32 \mathrm{~cm}$. Based on the data from these 12 tide gauges (Figs. 1, 4, 5), distributed over a wide area with dimensions of $1000 \mathrm{~km}$ (length) $\times 700 \mathrm{~km}$ (width), and also on field survey results by Salaree et al. (2018), we may conclude that the Dayyer tsunami was mainly a very local event. The timing of the surges/waves at different locations (Fig. 4, 5) reveals an approximately west-east propagation track of the storm consistent with the direction of the sand storm propagation (Fig. 3). Based on our visual inspection of these 12 sea level records, the visible period of the observed extreme waves is in the range of 10-40 min, with a dominant wave period of 15-20 min. The latter period appears at most stations.

\subsection{Spectral and Wavelet Analyses}

The considerable difference in energy between the background and event spectra is apparent. The "tsunami" spectrum at both stations (Dayyer and Asaluyeh) occupies a relatively broad frequency band between approximately 0.25 and $5 \mathrm{cph}$ (periods from $4 \mathrm{~h}$ to $12 \mathrm{~min}$ ). A very important feature became evident from the spectral analysis of the Dayyer record. It is well known that the frequencies of tsunami and background spectral peaks at each station are almost the same (cf. Honda et al. 1908). The matching of the spectral frequencies is related to the dominant role of the local/regional topography over the individual characteristics of the tsunami source (Rabinovich 1997). That is why, tsunami spectra from different events at each site are very similar. Recently, this was (again) clearly demonstrated for a great number of Mexican stations that recorded several 2010-2017 tsunamis (Zaytsev et al. 2017). The same is true for meteorological tsunamis (Monserrat et al. 1998; Marcos et al. 2009). The very steady periods of meteotsunamis in various bays and harbours of the world oceans, where such events occur regularly, are well known. These periods are normally associated with the fundamental (Helmholtz) mode of the corresponding basin (Rabinovich 2009): for example, $10.5 \mathrm{~min}$ in Ciutadella Harbour, Menorca Island, Spain (Rabinovich and Monserrat 1996), $20 \mathrm{~min}$ in Vela Luka Bay, Korčula Island, Croatia (Šepić et al. 2016) and $\sim 35$ min in Nagasaki Bay, Japan (Hibiya and Kajiura 1982). However, the background spectrum at Dayyer (Fig. 6a) does not have any evident spectral peaks, except a broad peak with a central period of $\sim 13.5$ min. In contrast, the tsunami (event) spectrum has a number of peaks, in particular at $1.8 \mathrm{~h}, 55 \mathrm{~min}$ and $18 \mathrm{~min}$, while there is no peak at $13.5 \mathrm{~min}$ (Fig. 6a). This difference between tsunami and background spectra is important evidence that the observed properties of the tsunami spectrum, including the spectral peaks, are related to the external forcing (i.e. to atmospheric processes) rather than to the resonant features of the local topography, and that the entire event is not associated with "harbour resonance", as at the sites listed above.

The spectra at Asaluyeh (Fig. 6b) have a quite different character than the spectra at Dayyer; the tsunami spectrum has spectral peaks at periods $1.4 \mathrm{~h}$ and 49, 22 and $14.5 \mathrm{~min}$, and the same peaks, but much weaker, are also seen in the background spectrum. Thus, significant atmospherically induced ocean waves, incoming from the open part of the PG, generate "harbour oscillations" (cf. Rabinovich 2009) at this station or, more precisely, amplify 
(a) Original records
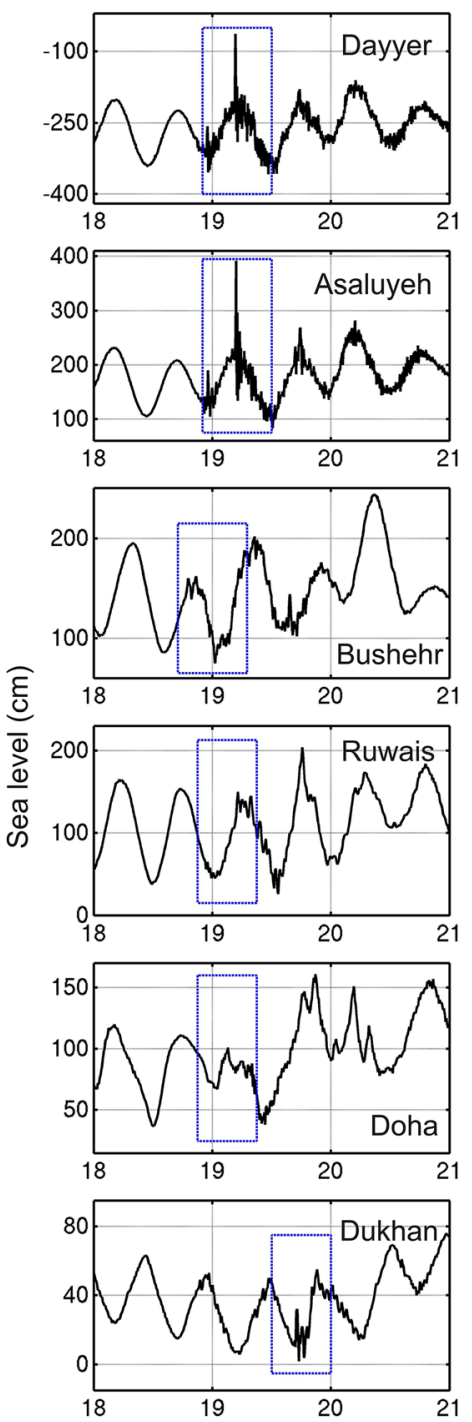

Time (UTC days) in March 2017 (b) De-tided records
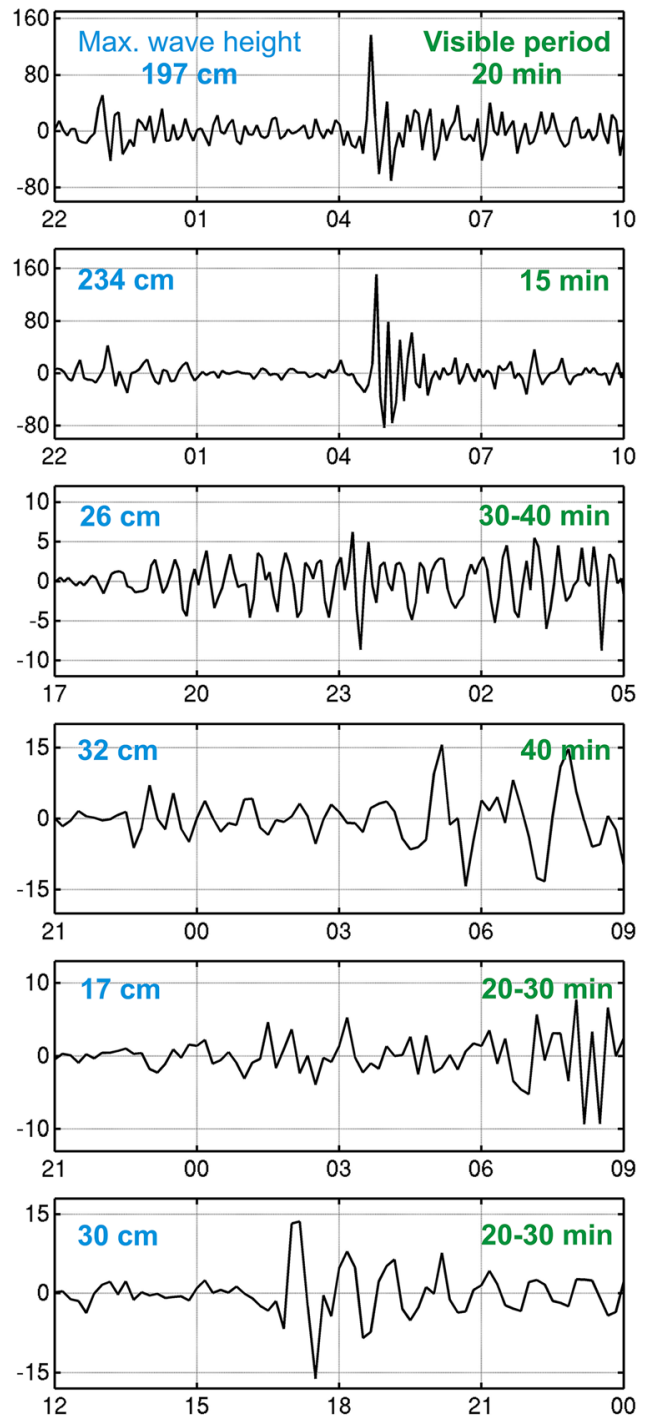

Time (UTC hours)

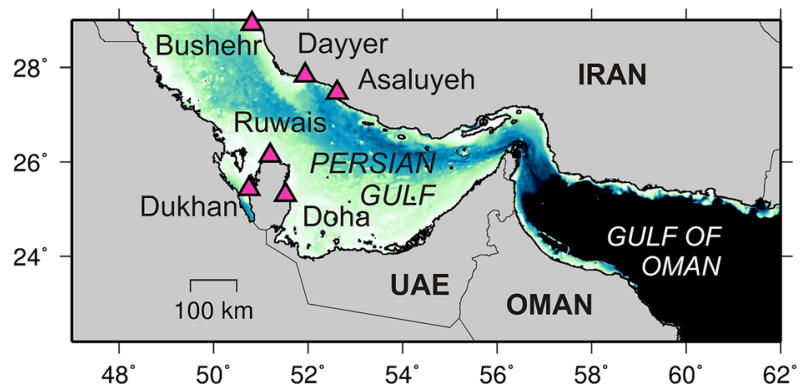

Figure 4

Recorded sea level waveforms for the period 18-21 March 2017 for the tide gauges located inside the Persian Gulf. a Original tide gauge records. b De-tided records. The blue numbers are the maximum trough-to-crest wave heights. Visible wave periods are denoted by green 
(a) Original records
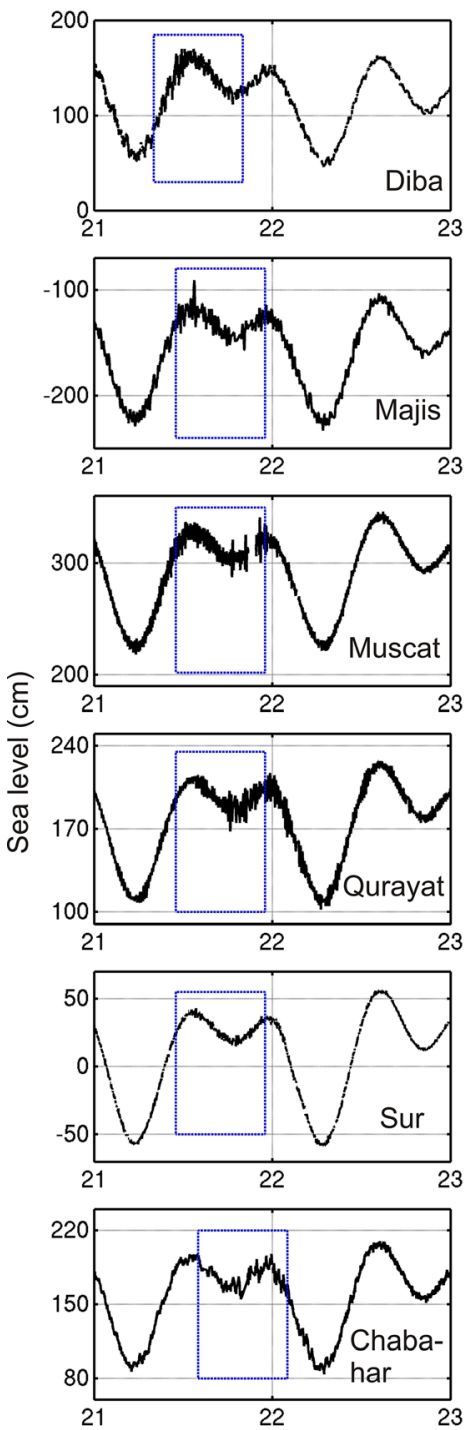

Time (UTC days) in March 2017 (b) De-tided records
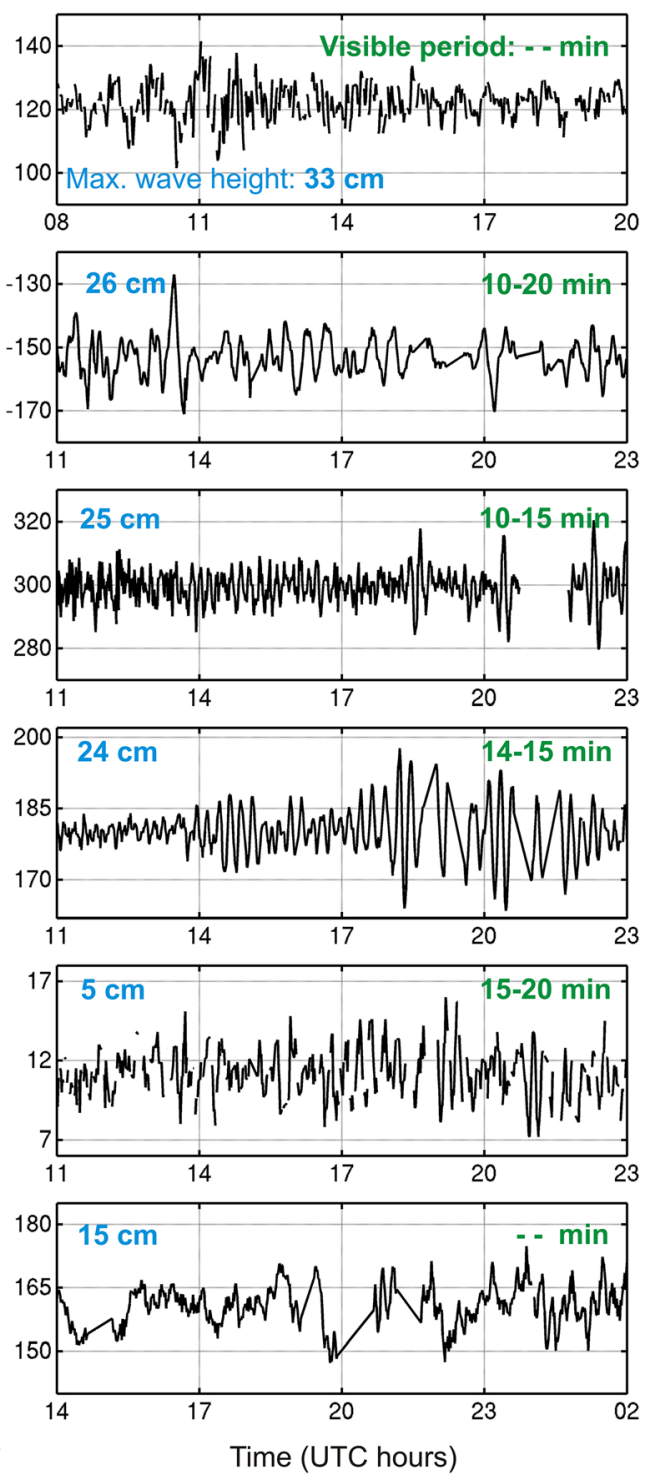

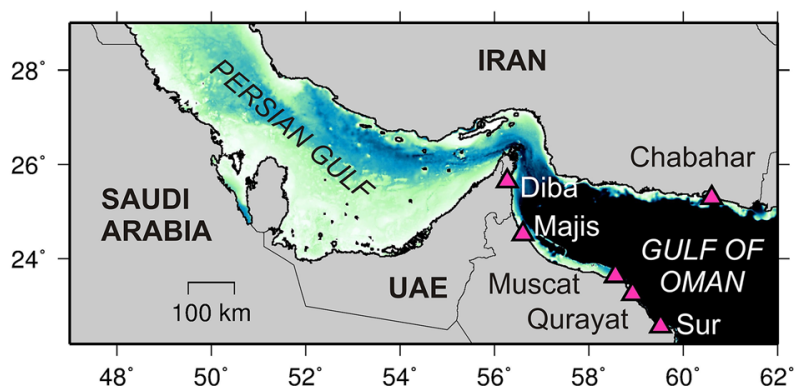

Figure 5

Recorded sea level waveforms for the period 21-23 March 2017 for the tide gauges located outside the Persian Gulf. a Original tide gauge records. b De-tided records. The blue numbers are the maximum trough-to-crest wave heights 


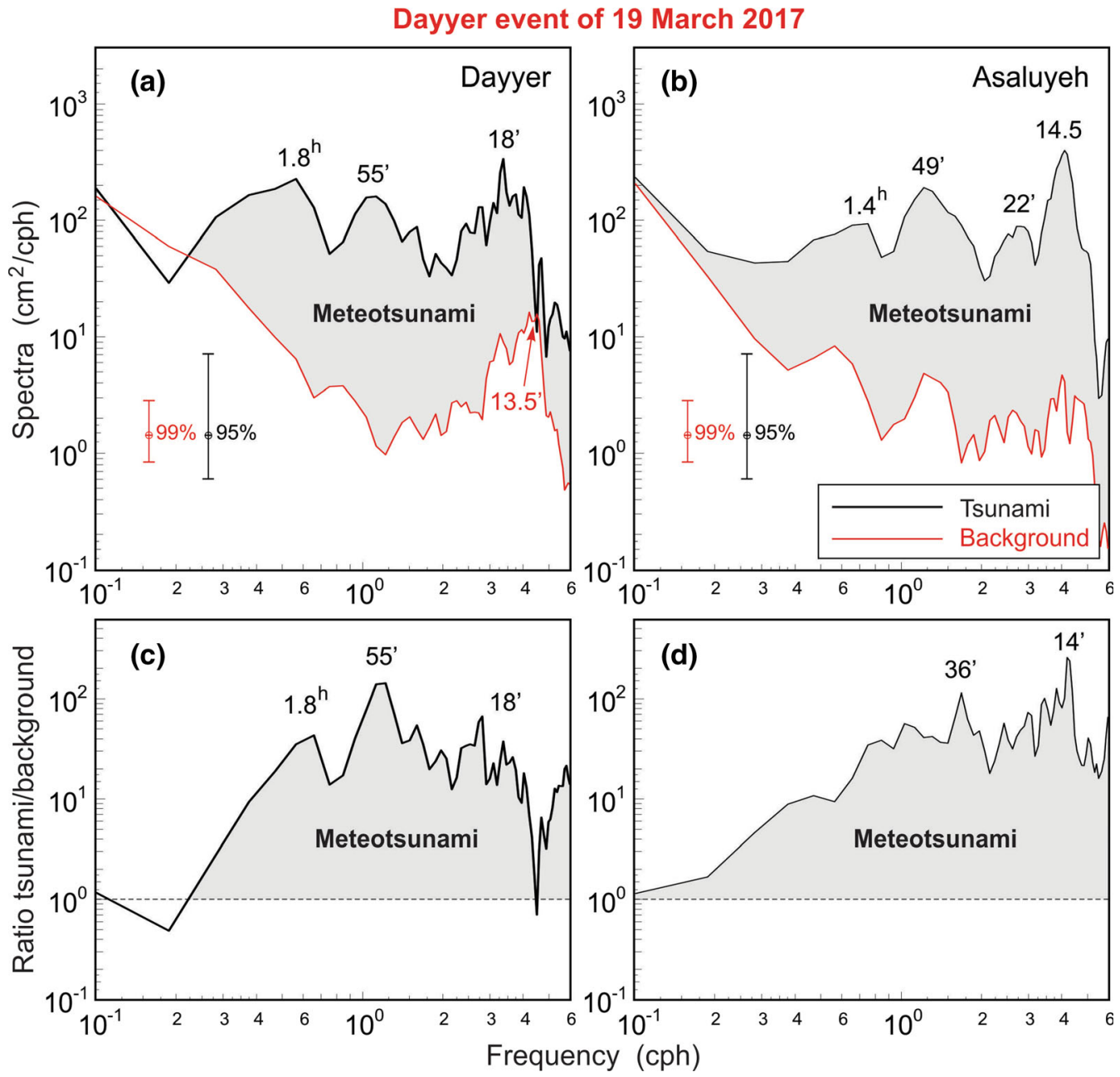

Figure 6

Spectra of the meteotsunami event of 19 March 2017 and the background sea level oscillations at a Dayyer and b Asaluyeh and spectral ratios (tsunami/background) at c Dayyer and d Asaluyeh

harbour (seiche) oscillations which already existed at this site. The strongest tsunami oscillations were at periods of 49 and $14.5 \mathrm{~min}$.

Figure $6 \mathrm{c}, \mathrm{d}$ show the computed tsunami/background ratios, $R(\omega)$, for Dayyer and Asaluyeh, respectively. The general shape and absolute values of these two functions look alike but specific features are different. At Dayyer two ratio peaks, $1.8 \mathrm{~h}$ and $55 \mathrm{~min}$, are the same as the peaks of the corresponding tsunami spectrum, but the peak with a period of $18 \mathrm{~min}$ is relatively much weaker (Fig. 6a, c). These results support the assumption that the observed spectral peaks at this station are caused by the particular properties of the external (atmospheric) forcing. The situation at Asaluyeh is dissimilar: three marked peaks in the tsunami spectrum at this station, $1.4 \mathrm{~h}, 49$, and $22 \mathrm{~min}$ (Fig. 6b) are absent in the spectral ratio, while there is a prominent peak with a period of $36 \mathrm{~min}$. It is evident that the latter peak is associated with the spectral properties of the forcing. There is only one peak that has a similar period in both the tsunami spectrum and in the spectral ratio: 14.5 and $14 \mathrm{~min}$, respectively (Fig. 6b, d). The closeness of these two peaks indicates the resonant interaction between the forcing oscillations with this period (14 min) and the natural (eigen) period (14.5 min) of the Asaluyeh harbour. 
The results of the wavelet $(f-t)$ analysis of three Iranian sea level records, Bushehr, Dayyer and Asaluyeh (Fig. 7), give us some additional information about the properties of the measured oscillations. At Bushehr (the upper plot) these oscillations had relatively chaotic character and occupied a wide range of periods. Noticeable oscillations at this station were observed for about 1.5 days (from $\sim$ 18:00 on 18 March to 6:00 on 20 March). At the two other stations, they also lasted for $\sim 1.5$ days (00:00 on 19 March to 12:00 on 20 March), however the extreme event itself was very short, only about 30-40 min (compare with Fig. 4b). According to the results of $f-t$ analysis, the periods of extreme oscillations were about $14-18 \mathrm{~min}$, in good agreement with the visible dominant periods at the respective records (Fig. 4b). These periods are comparable with those of moderate earthquake-generated tsunamis (e.g. Heidarzadeh et al. 2015). For instance, the July $2017 M_{\mathrm{w}} 6.6$ earthquake in Turkey-Greece generated tsunami waves with peak energy at periods of 7-13 min (Heidarzadeh et al. 2017). Additional lower frequency oscillations with a period of about $50 \mathrm{~min}$ are also evident in the $f-t$ diagrams of Dayyer and Asaluyeh, in agreement with what was seen in the spectra at the corresponding stations (Fig. 6a, b).

In general, the $f-t$ diagrams for Dayyer and Asaluyeh are very similar, both in time and frequency (Fig. 7), demonstrating high correlation of the extreme events at these two sites. At the same time, these diagrams, together with the records themselves (Fig. 4) and the results of their spectral analysis (Fig. 6a, b), indicate that the physical properties of generated meteotsunamis at these two sites were slightly different. The first arriving waves at Dayyer and Asaluyeh look almost identical, but then we see the difference (see two upper plots in Fig. 4b). The meteotsunami at Dayyer had the character of a solitary wave ("solitone"), typical for "beach meteotsunamis". Only one impulse-type oscillation is seen at this site, similar to the wave that was recorded at Panama City, Florida on 28 March 2014 (Olabarrieta et al. 2017) and the wave which impacted Odessa beaches, Ukraine on 27 June 2014 (Šepić et al. 2018b). At Asaluyeh, the initial soliton wave came into the harbour and generated seiches within the harbour. One of the dominant periods of

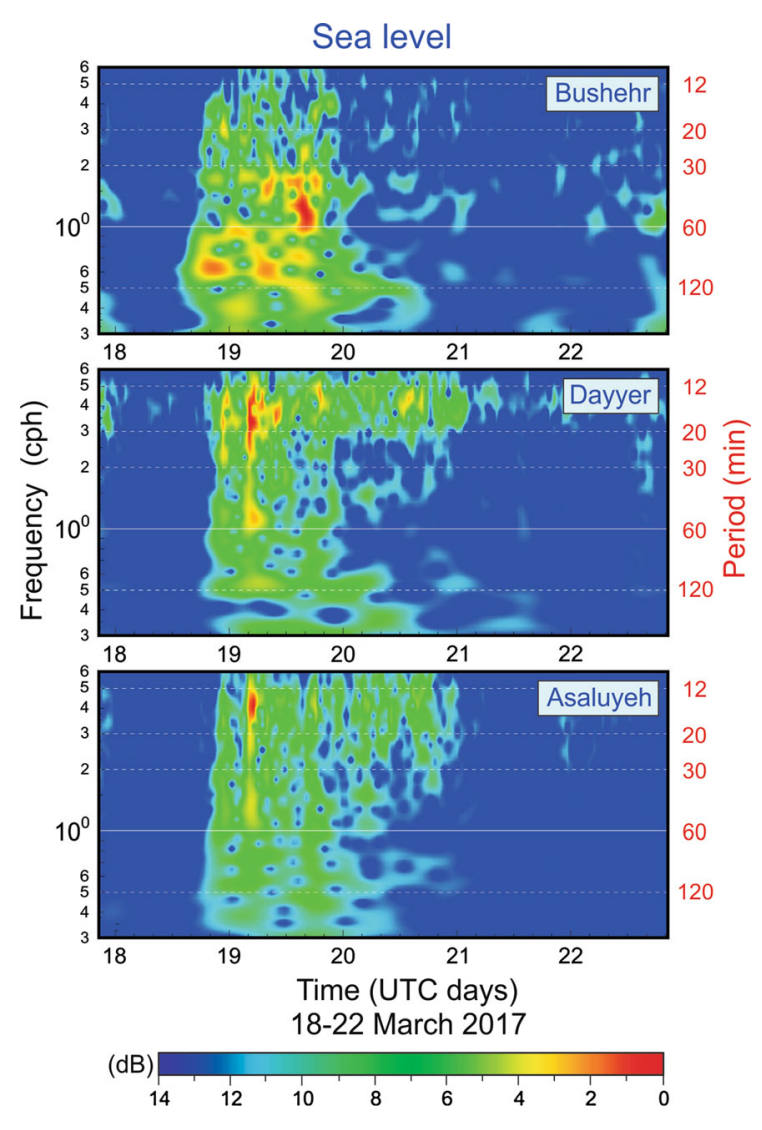

Figure 7

Frequency-time plots ( $f-t$ diagrams), which are similar to wavelets, of sea level oscillations on 18-23 March 2017 at Bushehr, Dayyer and Asaluyeh stations located along the Iranian coast of the Persian Gulf. The colormap shows high wave energy with red and low energy with dark blue colours

the external forcing (14 min) almost coincided with one of the resonant periods of this particular site (14.5 min), i.e. with one of the harbour modes. Thus, at this site the event had some features of a "harbour meteotsunami", but without pumping additional energy from the gulf, the generated harbour oscillations decayed very quickly (the second plot in Fig. 4b and the respective $f-t$ diagram). The situation where at one site the event had the character of a "beach meteotsunami" and at another site the character of a "harbour meteotsunami" is not unique: during the chain of meteotsunami events of 23-27 June 2014 in the Mediterranean and Black seas, at Ciutadella Harbour (Šepić et al. 2015) and in bays and harbours of the Croatian coast (Šepić et al. 2016) "harbour meteotsunamis" occurred, while the wave at Odessa (Šepić et al. 2018b) was a typical "beach meteotsunami". 
As the sampling interval for all three sea level records was $5 \mathrm{~min}$, the spectral and wavelet analyses only include periods longer than $10 \mathrm{~min}$. Relatively high energy at a period of about $10 \mathrm{~min}$ (Fig. 6a, b), corresponding to the Nyquist frequency, indicates the presence of shorter-period oscillations that could probably substantially amplify the harmfulness of the event. Unfortunately, we do not have the data that could be used to examine this effect.

\section{Results of Atmospheric Analysis}

\subsection{Synoptic Setting}

The results presented in Sects. 2-4, as well as findings of Salaree et al. (2018), indicate that the catastrophic event of 19 March 2017 in Dayyer (Iran) was caused by atmospheric processes. However, it remained unclear what was the exact atmospheric phenomenon or pressure disturbance that produced so strong an effect and the physical mechanism responsible for generation of the meteotsunami at this particular site. That is why, we paid specific attention to the analysis of the general synoptic situation over the Persian Gulf and to the examination of all available atmospheric pressure records.

A well-developed cyclone, characterized by a minimum air pressure of $\sim 1002 \mathrm{hPa}$, was centred over eastern Libya during the midday hours of 17 March 2017 (Fig. 8, upper left). Strong surface winds, associated with the cyclone, generated dust storms in Libya (Fig. 3). Estimated surface wind speeds on the back side of the cyclone were up to $16 \mathrm{~m} / \mathrm{s}$ (not shown). Within next two days, the cyclone advanced eastward, centering over Saudi Arabia on 18 March, and over Iraq one day later. The cyclone's propagation to Egypt and the Arabian Peninsula initiated strong surface winds and disruptive sand storms (Fig. 3). Following the midday hours of 19 March, the propagation direction of the cyclone changed to southeastward, and at 12:00 UTC on 20 March it reached the southeastern part of the Arabian Peninsula (Fig. 8). The propagation of the cyclone was accompanied by a low-level inflow of warm and dry air on its frontal side and cold and humid air on the rear side, resulting in strong temperature and humidity gradients across the area and in convective storms. During the initial stage, the cyclone spread vertically up to the level of 500-hPa (seen as cut-off low on 17 and 18 March) and then its midtroposphere component deteriorated to an upper-level trough (Fig. 8). A strong jet stream with westerly to southwesterly winds was formed at the southern end of the 500-hPa trough, roughly following the positioning of the low-level cyclone. Wind speeds over the PG reached more than $40 \mathrm{~m} / \mathrm{s}$ within the jet core, and this lasted throughout the entire period of 19-21 March 2017, i.e. precisely when the tsunami event occurred. A very similar situation was observed over the Mediterranean region on 23-27 June 2014 when the location and timing of individual meteotsunami events were closely correlated with the position and evolution of the jet stream (Šepić et al. 2015).

\subsection{Air Pressure Disturbances Causing Sea Level Oscillations}

Although we did not have high-resolution surface pressure data from the Iranian coast, the air pressure records from other countries located along the PG were found to be very useful. They show that during the period of 17-21 March 2017, which includes the tsunami event, a number of substantial, potentially tsunamigenic, pressure disturbances propagated over the PG. Concurrent with the cyclone's arrival around noon on 18 March 2017 (Fig. 8), the air pressure started to drop rapidly at most stations in the region (Fig. 9); the minimum low pressure occurred approximately 24-48 h later (on 19-20 March), first in Kuwait, Saudi Arabia, Bahrain and Qatar, and later in the United Arab Emirates and Oman (Fig. 9). According to Fig. 9, prominent pressure fluctuations were observed over the entire region. The atmospheric processes during the period 17-21 March 2017 were very active in the PG region and favourable for thunderstorms and strong wind waves. Some destructive effects of such storms across the PG region are shown in Fig. 3.

We used high-pass filtering of the air pressure time series with a 3-h Kaiser-Bessel window (cf. Thomson and Emery 2014) to isolate particular pressure disturbances (Fig. 10). It appears that the cyclone's propagation over the PG was accompanied 

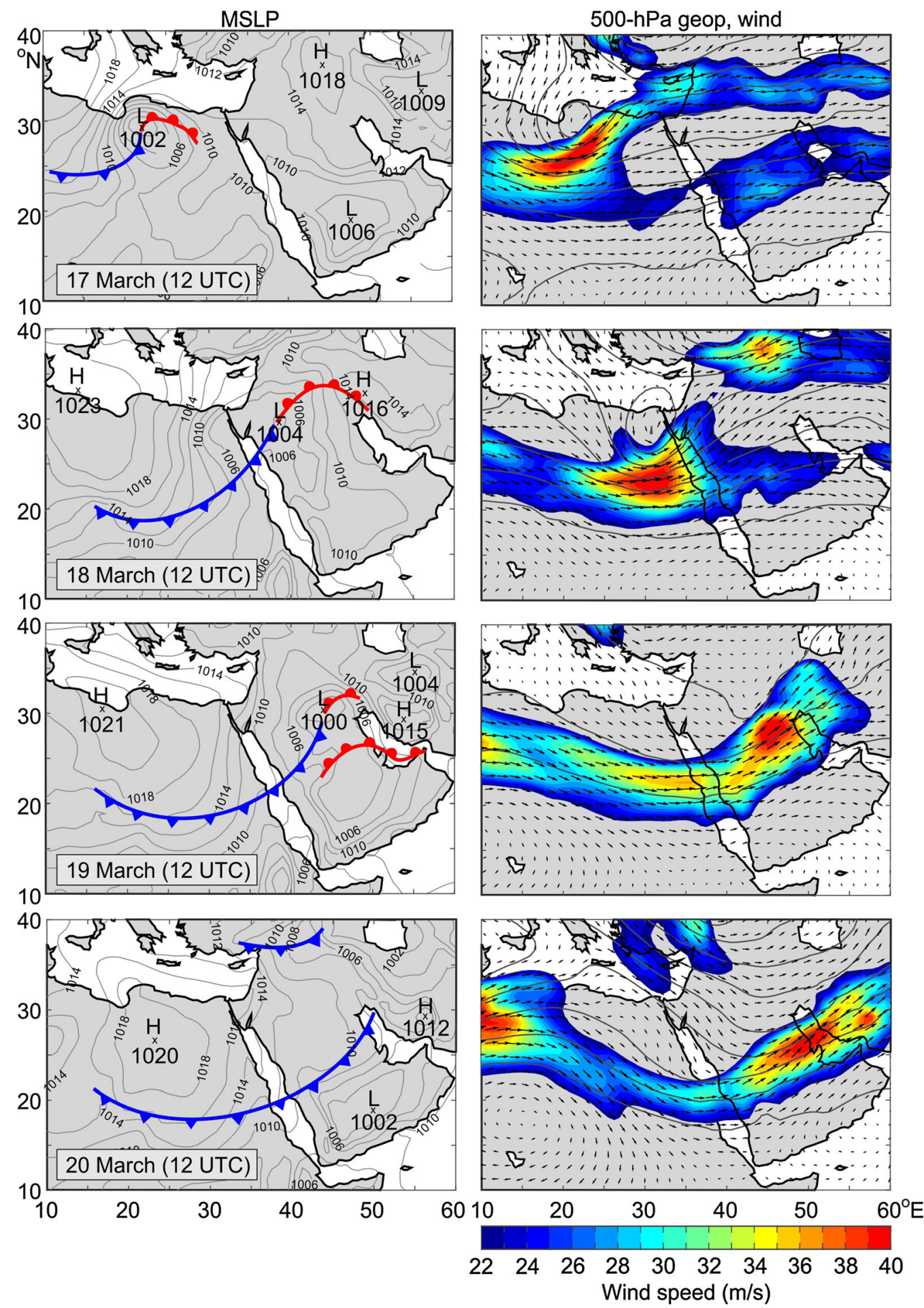

Figure 8

Temporal and spatial evolution of the synoptic situation across the northeastern Africa and Middle East regions for the period of 17-20 March 2017 for: (left column) sea surface pressure and temperature fronts; and (right column) 500-hPa geopotential height and wind fields 


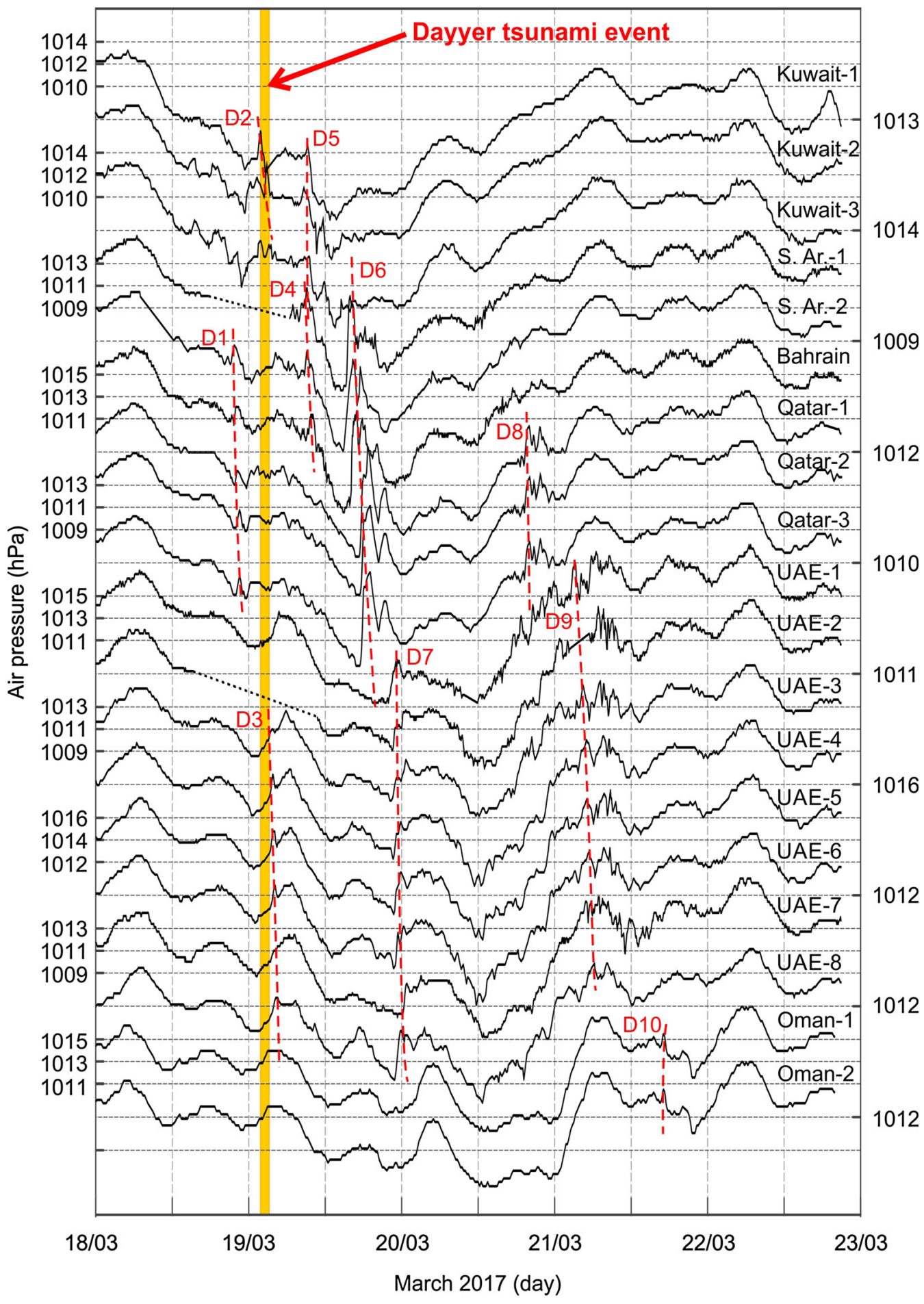

Figure 9

Air pressure time series measured at Wunderground meteorological stations. Shaded yellow band indicates the time of the Dayyer tsunami; the red dashed lines denote distinct air pressure disturbances (D1-D10) 


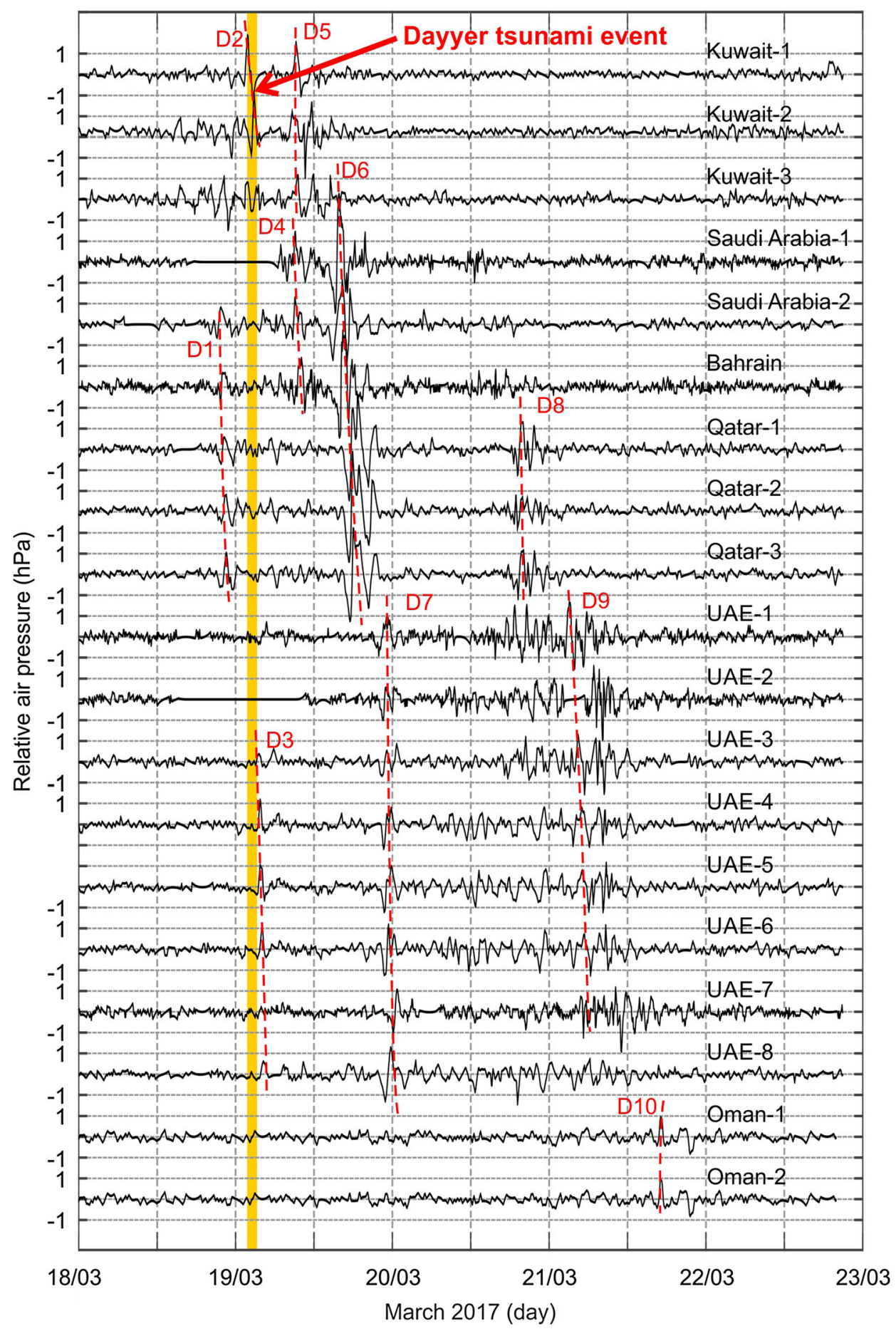

Figure 10

Relative air pressure time series measured at Wunderground meteorological stations. The records were high-pass filtered with a 3-h KaiserBessel window. Shaded yellow band indicates the time of the Dayyer tsunami; the red dashed lines denote distinct air pressure disturbances (D1-D10) 
Table 2

Main characteristics of atmospheric disturbances recorded during 18-21 March 2017 over the PG

\begin{tabular}{llllllll}
\hline Disturbance & Date (March 2017) & Time (UTC) & Countries & Period (min) & Height (hPa) & $\mathrm{RC}_{\max }^{\mathrm{c}}(\mathrm{hPa} / 5$ min) & Type \\
\hline D1 & 18 & $21: 00-24: 00$ & Bahrain, Qatar & 110 & 1.6 & 0.4 & Single \\
D2 & 19 & $01: 00-04: 00$ & Kuwait & 68 & 3.1 & 1.3 & Single \\
D3 & 19 & $03: 00-05: 00$ & UAE $^{\mathrm{a}}$ & 60 & 1.7 & -0.5 & Single \\
D4 & 19 & $06: 00-11: 00$ & SA $^{\mathrm{b}}$, Bahrain & 60 & 2.6 & 0.5 & Multiple \\
D5 & 19 & $08: 00-11: 00$ & Kuwait $_{2}$ & 95 & 2.6 & 1.4 & Single/double \\
D6 & 19 & $15: 00-21: 00$ & SA, Qatar, Bahrain & 90 & 5.7 & 3.0 & Single/double \\
D7 & $19-20$ & $22: 00-01: 00$ & UAE & 65 & 2.6 & 0.7 & Single/double \\
D8 & 20 & $18: 00-23: 00$ & Qatar & 57 & 2.6 & 1.3 & Multiple \\
D9 & $20-21$ & $17: 00-10: 00$ & UAE & 66 & 3.2 & 2.7 & Multiple \\
D10 & 21 & $16: 00-18: 00$ & Oman & 77 & 1.4 & 0.4 & Single \\
\hline
\end{tabular}

${ }^{\mathrm{a}}$ The United Arab Emirates

${ }^{\mathrm{b}}$ Saudi Arabia

${ }^{\mathrm{c}}$ Maximum 5-min rate of air pressure change

by intense high-frequency air pressure oscillations. These disturbances had higher magnitudes and shorter train durations (one-two oscillations), specifically at the time of the cyclone's passage over the region and lower magnitudes/longer durations (multiple oscillations at each station) when the cyclone was departing from the region. We identified ten distinctive disturbances, i.e. periods with intensified high-frequency activity in air pressure records; they are marked as D1-D10 in Figs. 9 and 10, while their main characteristics are given in Table 2. For the multiple-disturbance events, we marked only the most pronounced disturbance.

The two strongest consequent disturbances were recorded in Saudi Arabia, Bahrain and Qatar in the afternoon hours of 19 March. The first had a maximum peak-to-trough height of $5.7 \mathrm{hPa}$, a very abrupt air pressure change of $3.0 \mathrm{hPa} / 5 \mathrm{~min}$, and a duration of $\sim 90 \mathrm{~min}$. The second disturbance had a similar duration, but with a lower maximum measured magnitude of $3.0 \mathrm{hPa}$ and a slower rate of $1.1 \mathrm{hPa} / 5 \mathrm{~min}$. The first disturbance had a substantial tsunamigenic potential, whereas the second disturbance was also potentially tsunamigenic, but slightly weaker. Other important disturbances are: (1) D2 and (2) D5 which were recorded over Kuwait during the morning hours of 19 March, with an air pressure rate of change of up to $1.4 \mathrm{hPa} / 5 \mathrm{~min}$; (3) a series of disturbances indicated as D8 that were recorded over Qatar during the night time hours of 20 March, which had a rate of up to $1.3 \mathrm{hPa} / 5 \mathrm{~min}$; and (4) another prolonged series of disturbances measured over the United Arab Emirates (D9) during 20-21 March, with rates as high as $2.7 \mathrm{hPa} / 5 \mathrm{~min}$.

It is interesting that at the time of the Dayyer tsunami (indicated by the yellow band in Figs. 9, 10), distinct atmospheric pressure disturbances, D2 and D3, were recorded only at the Kuwait and UAE stations, respectively. However, these stations are located more than $400 \mathrm{~km}$ away from Dayyer, and it is highly unlikely that these particular disturbances were related to the observed tsunami at Dayyer. It is more probable that the atmospheric disturbances responsible for the Dayyer event were simply not captured by the Wunderground measurement network. This is not surprising, since atmospheric disturbances responsible for meteotsunamis have typically small spatial dimensions $(20-60 \mathrm{~km})$ and short life cycle (a few hours) (cf. Thomson et al. 2009; Ličer et al. 2017) and thus were not properly captured by available measurement networks, which had no stations in the area of Dayyer. Nevertheless, we may conclude that our analysis of the atmospheric pressure records demonstrates that atmospheric conditions over the PG were highly favourable for generation of tsunamigenic disturbances during 18-21 March 2017, with the most intense disturbances occurring over the middle part of the PG precisely on 19 March.

The indicated properties of the observed atmospheric disturbances in the area of the PG are clearly seen in the $f-t$ (wavelet) plots for the atmospheric 

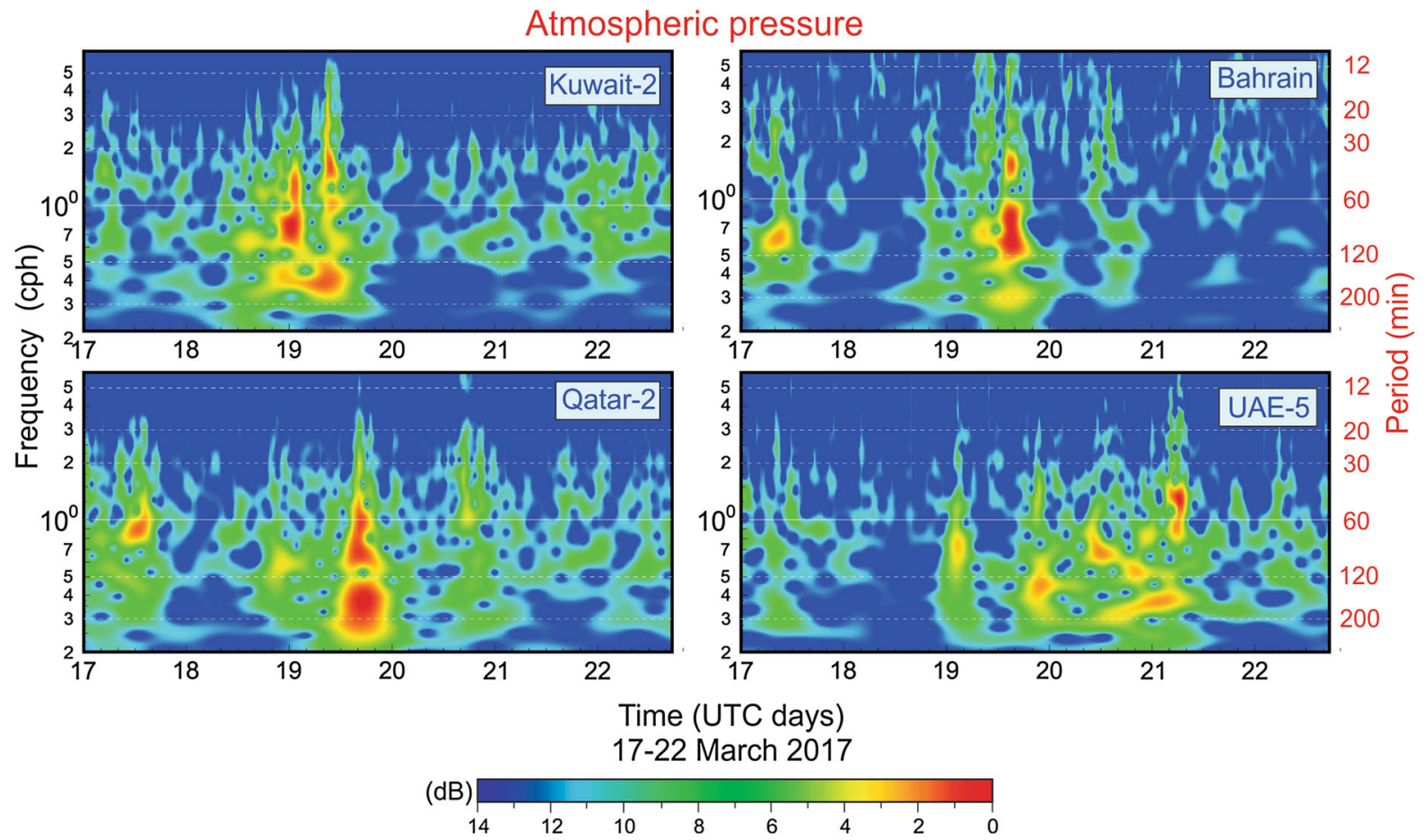

Figure 11

Frequency-time plots ( $f-t$ diagrams) for the atmospheric pressure records at four stations: Kuwait-2, Bahrain, Qatar-2 and UAE-5 (the corresponding records are shown in Fig. 10)

pressure fluctuations presented in Fig. 11, in particular:

- The entire period of 19-21 March 2017 is characterized by prominent activity of high-frequency atmospheric processes;

- The main frequency band of the corresponding disturbances is $0.3-3.0 \mathrm{cph}$ (i.e. periods of 20-200 min);

- A specific feature of the observed disturbances is high spatial variability (for example, poor correlation between these disturbances at UAE- 5 and at other stations, located nearby) and quite short life cycle (only a few hours).

In general, we may say, that although we cannot identify the exact atmospheric disturbance responsible for the Dayyer event, we see that there were several strong disturbances during the period which includes this event, and that the entire atmospheric situation over the Persian Gulf was very similar to the one observed in the Mediterranean/Black Sea region on 23-27 June 2014 ("tumultuous atmosphere"), which triggered a number of devastating meteotsunamis in various parts of the region (Šepić et al. 2015).

\subsection{Propagation Velocity of Atmospheric Pressure Disturbances}

To examine whether the Proudman resonance took place in the central region of the PG (in the vicinity of Dayyer), i.e. if the speed of atmospheric pressure disturbances $(U)$ was equal or close to the speed of long ocean waves $(c)$, we need to determine the propagation speed and direction of the air pressure disturbances in this region. For selected disturbances (D2, D5 and D6), i.e. for those where we could pin-point the arrival time of the same peak/ trough at three or more stations, we have estimated propagation speed and direction using the LSM approach to this problem described by Thomson et al. (2009). The results of analysis are presented in Table 3.

Unfortunately, our analysis demonstrated that the velocity parameters estimated from two sets of stations are inconsistent and, therefore, not reliable 
Table 3

Velocity parameters of selected air pressure disturbances in the PG region, estimated: (1) for all stations which recorded this disturbance, and (2) for selected stations only

\begin{tabular}{|c|c|c|c|c|c|c|c|c|c|c|}
\hline \multirow[t]{2}{*}{ Disturbance } & \multicolumn{5}{|c|}{ All stations } & \multicolumn{5}{|c|}{ Selected stations } \\
\hline & No. & $U(\mathrm{~m} / \mathrm{s})^{\mathrm{a}}$ & $\varepsilon_{u}(\mathrm{~m} / \mathrm{s})^{\mathrm{a}}$ & $\gamma\left({ }^{\circ}\right)^{\mathrm{a}}$ & $\varepsilon_{\gamma}\left({ }^{\circ}\right)^{\mathrm{a}}$ & No. & $U(\mathrm{~m} / \mathrm{s})$ & $\varepsilon_{u}(\mathrm{~m} / \mathrm{s})$ & $\gamma\left({ }^{\circ}\right)$ & $\varepsilon_{\gamma}\left({ }^{\circ}\right)$ \\
\hline $\mathrm{D} 2$ & 5 & 8.1 & 2.6 & 150.5 & 43.7 & 3 & 3.9 & N/A & 90.6 & N/A \\
\hline D5 & 6 & 17.7 & 51.4 & 70.4 & 17.2 & 3 & 0.7 & N/A & 71.1 & N/A \\
\hline D6 & 12 & 18.2 & 2.2 & 138.9 & 41.9 & 7 & 18.0 & 7.1 & 145.6 & 78.8 \\
\hline
\end{tabular}

${ }^{\mathrm{a}}$ For each disturbance and estimate, the following parameters are indicated: Number of stations used in the calculation (No.), the computed disturbance speed $(U)$ and the speed error $\left(\varepsilon_{\mathrm{u}}\right)$, the computed direction $\left(\gamma\right.$-true North) and the direction error $\left(\varepsilon_{\gamma}\right)$; "N/A" indicates that number of stations was insufficient to estimate speed and direction errors. For calculation of disturbance direction, we applied the oceanographic convention, i.e. the direction to a specific azimuth

Table 4

The $500 \mathrm{hPa}$ wind speed $(u)$ and the speed error $\left(\varepsilon_{u}\right)$, the direction $(\gamma)$, and the direction error $\left(\varepsilon_{\gamma}\right)$, estimated from the ERA-Interim dataset at times and points closest to the times and areas of appearance of the PG disturbances and the Dayyer tsunami

\begin{tabular}{llllr}
\hline Disturbance & Time (date, UTC h) & $u(\mathrm{~m} / \mathrm{s})$ & $\varepsilon_{u}(\mathrm{~m} / \mathrm{s})$ & $\gamma\left({ }^{\circ}\right)^{\mathrm{a}}$ \\
\hline D1 & 18 March, 21:00-24:00 & 23.4 & 1.5 & 259.4 \\
D2 & 19 March, 01:00-04:00 & 29.4 & 3.1 & 240.2 \\
D3 & 19 March, 03:00-05:00 & 21.4 & 2.2 & 269.6 \\
DX (Dayyer) & 19 March, 05:00 & 26.1 & 2.2 & 256.6 \\
D4 & 19 March, 06:00-11:00 & 26.8 & 2.0 & 250.6 \\
D5 & 19 March, 08:00-11:00 & 35.3 & 4.6 & 238.2 \\
D6 & 19 March, 15:00-21:00 & 33.0 & 1.3 & 239.0 \\
D7 & 19-20 March, 22:00-01:00 & 27.0 & 1.7 & 242.0 \\
D8 & 20 March, 18:00-23:00 & 38.2 & 3.1 & 24.0 \\
D9 & 20-21 March, 17:00-10:00 & 31.5 & 4.4 & 3.8 \\
D10 & 21 March, 16:00-18:00 & 26.6 & 3.6 & 229.9 \\
\hline
\end{tabular}

${ }^{\mathrm{a}}$ For wind direction calculation, we applied the meteorological convention

enough. The main problem is the low time resolutions of the recorded air pressure series: the sampling interval of most stations was too long $(5 \mathrm{~min}$ for 6 stations, $15 \mathrm{~min}$ for 40 stations, and $25 \mathrm{~min}$ for one station). Such intervals do not allow us to determine the exact timing of the main peaks of the studied disturbances, which had typical periods from 60 to 110 min (Fig. 10; Table 2). Furthermore, most stations at which any individual disturbances have been recorded, are within a short distance $(<5 \mathrm{~km})$ from each other (Fig. 1; Table 2), i.e. the expected propagation time from one station to another was often within the sampling interval. The only exception is disturbance D6: this event was recorded by a large number of stations (Tables 2, 3; Fig. 10) located along an $\sim 200 \mathrm{~km}$ path, thus making its speed and direction estimates more reliable and coherent (Table 3). These estimates show that disturbance
D6 propagated southeastward, i.e. approximately along the PG axis, with a phase speed of $\sim 18 \mathrm{~m} / \mathrm{s}$, which is typical for tsunamigenic atmospheric disturbances (Monserrat and Thorpe 1996; Monserrat et al. 2006). However, our estimates cannot give us the exact information about the particular disturbance that caused the Dayyer disaster due to the absence of Wunderground pressure instruments in the vicinity of the affected coast.

Additionally for each disturbance (D1-D10), as well as for a probable disturbance responsible for the Dayyer tsunami (DX), we estimated the propagation velocity parameters from the ERA-Interim 500-hPa wind speed using two spatial points, closest to the disturbance area, and two temporal points, closest to the disturbance times. The results of our analysis are given in Table 4. We assume that the observed PG disturbances, as well as the DX disturbance, 
propagated with speeds and directions comparable with the listed wind parameters (Table 4). Generally, wind speeds were higher than $21 \mathrm{~m} / \mathrm{s}$ throughout the entire studied period, with the lowest values $(21.4 \mathrm{~m} /$ s) during the morning of 19 March (D3), and the highest values of $33-35.3 \mathrm{~m} / \mathrm{s}$ between 08:00 and 21:00 on 19 March (D5-D6), and $38.2 \mathrm{~m} / \mathrm{s}$ during the D8 event at 18:00-23:00 on 20 March. Throughout the period under study, the modelled 500-hPa winds were from the southwest/west. During the Dayyer event, the $500 \mathrm{hPa}$ wind had an estimated speed of $26.1 \mathrm{~m} / \mathrm{s}$ and direction (coming from) of $256.6^{\circ}$ (Table 4), i.e. it was directed precisely towards the Dayyer coast.

\subsection{Remote Sensing}

Analysis of satellite images can give us a muchneeded insight into the character of recorded atmospheric pressure disturbances. Figure 12 shows these images, which were processed to depict convective activity at the approximate time of the Dayyer tsunami (05:12 UTC), and at the times of the most intensive atmospheric pressure disturbances over the PG (D1-D10), identified in Fig. 10. It appears that most of the recorded disturbances were correlated with either convective clouds (D2, D4, D5 and D6) or with atmospheric gravity waves (D7 and D8); and only a few disturbances (D1, D3 and D9) were not clearly linked to the atmospheric cloud cover. We may assume that the latter events were not directly related to the convective activity; however this does not imply the absence of atmospheric waves, but rather that the gravity waves were either not visible because of the upper level clouds (D9), or because there was not enough moisture in the atmosphere to form the clouds (D1 and D3).

Convective activity over the PG was particularly strong between the evening hours of 18 March 2017 and the late afternoon hours of 19 March 2017, covering areas of up to $\sim 1000 \mathrm{~km}$ in diameter. In general, the area of high convective activity, moved from the northwest to the southeast, changing its major axis from NW-SE (up to the morning hours of 19 March) to SW-NE (during the afternoon hours of 19 March). Convective clouds can be seen over Dayyer at 21:57 UTC on 18 March 2017 (Fig. 12), i.e. close to the time of the onset of the recorded extreme sea level oscillations at the Dayyer and Asaluyeh tide gauges (Fig. 4). Furthermore, specifically at the time of the Dayyer tsunami, a series of convective clouds, organized in a wave-like pattern, was present over the area impacted by the tsunami waves (Fig. 12, 05:12 UTC). This agrees with eyewitness reports that pointed out that a strong thunderstorm preceded the Dayyer event. Intensive convective activity is a common feature that is known to precede or be concurrent with strong meteotsunamis (cf. Jansà et al. 2007; Wertman et al. 2014; Bechle et al. 2015). This is mainly related to the fact that convective storms, due to strong air updrafts and downdrafts, are frequently associated with abrupt air pressure changes, i.e. with tsunamigenic pressure jumps (Holton 2004). Another reason is the waveCISK mechanism, responsible for generation, amplification and propagation of atmospheric gravity waves (Powers and Reed 1993). In particular, the second mechanism was found to occur during several previous meteotsunami events (Belušić et al. 2007; Tanaka 2010; Horvath et al. 2018).

\section{Link between Air Pressure Disturbances and Sea Level Oscillations}

In Fig. 13, we show the maximum heights of high-frequency $(T<3 \mathrm{~h})$ atmospheric disturbances and sea level oscillations in the PG region for the simultaneous time intervals. They are overlaid by the 500-hPa wind contours, which can be used to illustrate the presence of a tsunamigenic synoptic pattern: several historical examples demonstrate that meteotsunamis are commonly associated with strong winds at the 500-hPa level (cf. Jansà et al. 2007; Thomson et al. 2009; Šepić et al. 2015). The reasons are twofold: (1) atmospheric gravity waves can be developed by atmospheric instabilities, occurring at locations of strong spatial gradients of the upper-level winds, in particular, at the jet stream exit regions (Wang and Zhang 2007); and (2) providing a stable atmospheric layer below, a 500-hPa wind can serve as a steering wind for ducted atmospheric gravity waves, allowing their prolonged propagation and, consequently, the meteotsunami generation (Monserrat and Thorpe 

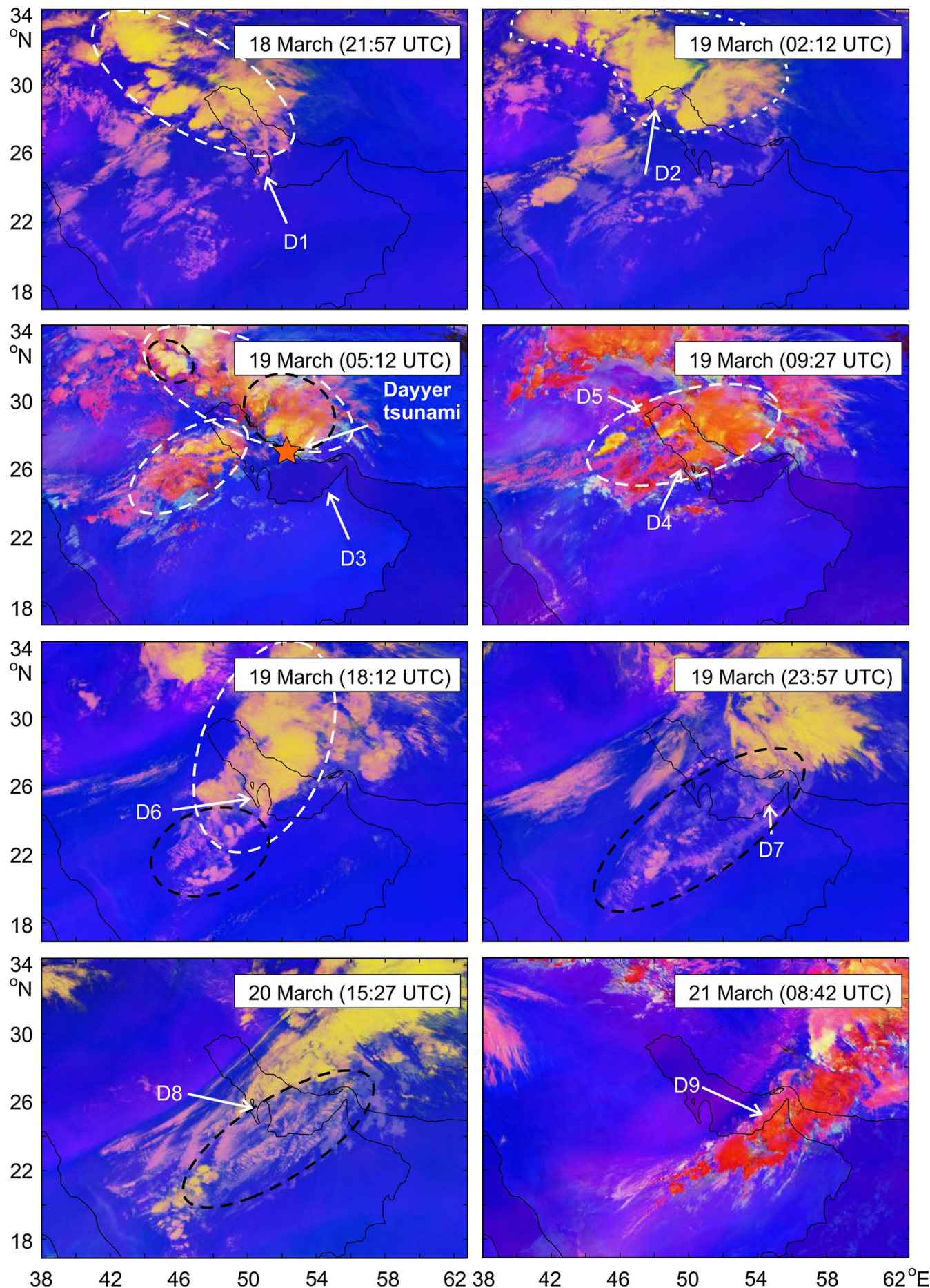

Figure 12

Sequence of satellite images illustrating propagation of clouds over the Middle East during 18-21 March 2017. The areas showing high concentration of convective clouds are encircled by white dashed lines, and the areas with high activity of atmospheric gravity waves are encircled by black dashed lines. Approximate locations of atmospheric disturbances marked in Figs. 9 and 10 (D1-D9) are indicated by white arrows at the respective times 

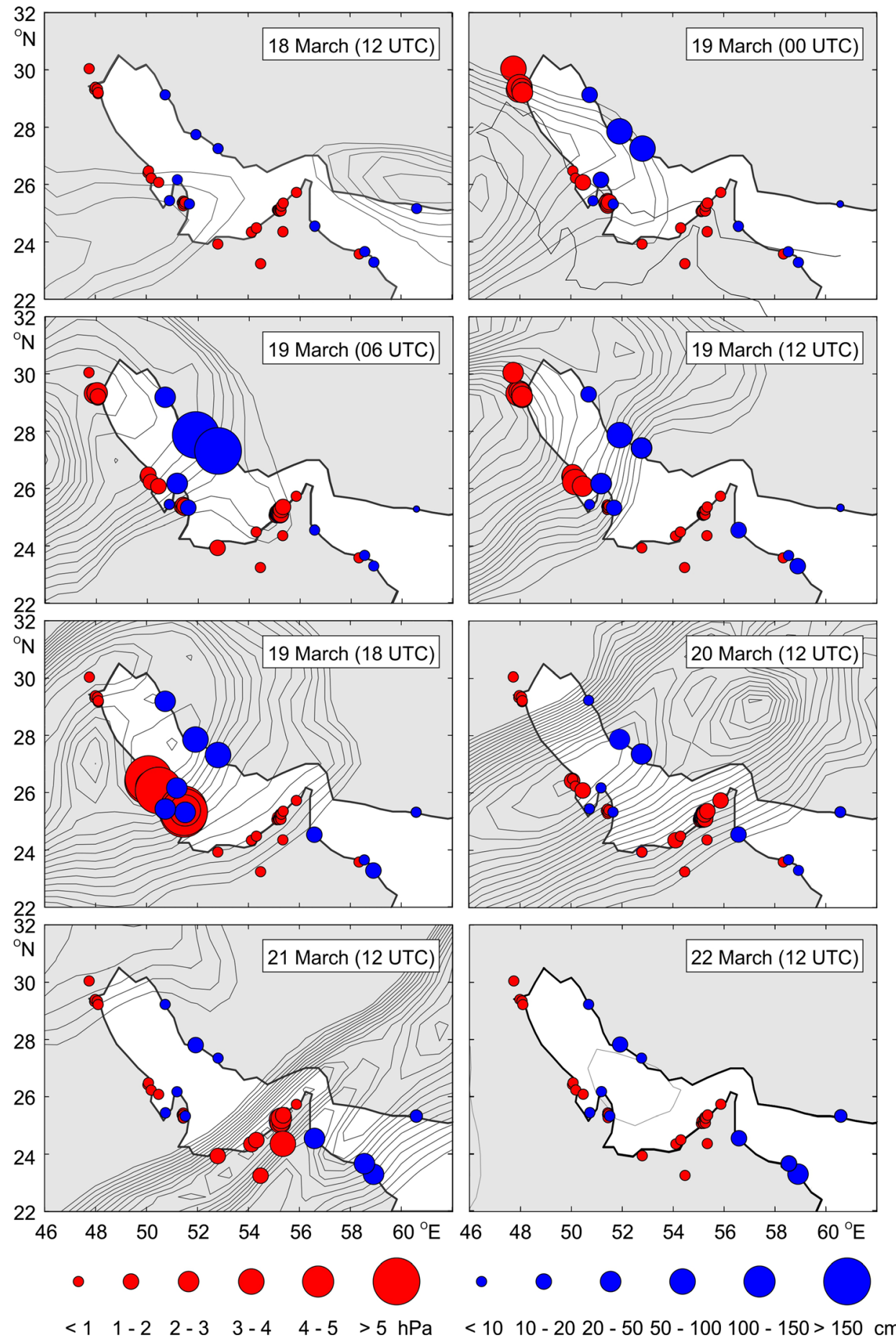

$<1 \quad 1-22-3 \quad 3-4 \quad 4-5>5 \mathrm{hPa}<1010-2020-5050-100100-150>150 \mathrm{~cm}$

Figure 13

Temporal and spatial evolution of trough-to-crest heights of high frequency (periods of $<3 \mathrm{~h}$ ) atmospheric pressure (red circles) and sea level (blue circles) oscillations in the PG region. The size of the circles is proportional to the oscillation height. The contours shown are at $1 \mathrm{~m} / \mathrm{s}$ intervals 
1996). Figure 13 shows that: (a) the intensification of atmospheric pressure activity is concurrent with the intensification of high-frequency sea level oscillations; and that (b) both are concurrent with the arrival of a favourable tsunamigenic synoptic pattern to the PG region. In particular, a day before the Dayyer tsunami (at 12:00 UTC on 18 March), no tsunamigenic atmospheric system was noticeable over the PG, and there was no high-frequency activity of either air pressure or sea level. Then, $12 \mathrm{~h}$ later (at 00:00 UTC of 19 March), a favourable synoptic system moved into the PG region, and was accompanied by high-frequency air pressure and sea level oscillations (Figs. 4, 7, 10, 11), in particular, in Kuwait (air pressure) and Iran (sea level stations), which were, at that time, located precisely at the leading edge of the jet stream. At the following examined time (06:00 UTC on 19 March), the region was still under the influence of a tsunamigenic synoptic pattern, and during this interval (00:00-06:00), the deadly tsunami waves impacted Dayyer. During the next $12 \mathrm{~h}$, high-frequency activity of both air pressure and sea level continued over the central PG region, reaching peak strength at some specific locations/times. In particular, high atmospheric activity was observed over Saudi Arabia, Bahrain and Qatar at 18 UTC on 19 March 2017. Later, on 20-21 March, the tsunamigenic atmospheric system kept slowly propagating eastward. This translation was accompanied by intensification of atmospheric and sea level oscillations at eastern stations: at 12 UTC on 21 March, the strongest air pressure disturbances were observed over the United Arab Emirates and the largest sea level oscillations in the Gulf of Oman. One day later, the tsunamigenic atmospheric system has traversed further to the east, out of the area of our interest, and high frequency sea level and atmospheric oscillations stopped being recorded in the PG region.

The co-occurrence of a tsunamigenic synoptic pattern and high-frequency atmospheric/sea level oscillations implies that air pressure disturbances were the main generating force of extreme sea level oscillations in the PG region. However, despite the atmospheric activity during the afternoon hours of 19 March, which was strong all over the PG region, especially over Saudi Arabia, Bahrain and Qatar, destructive tsunami waves occurred only at a limited stretch of the coast. Whereas recorded sea level oscillations at the central Iranian coast were up to $234 \mathrm{~cm}$ (while eye-witness reports and land marks indicate runup heights of $>3 \mathrm{~m}$, see Salaree et al. 2018), the sea level oscillations at non-Iranian stations had a maximum height of only $33 \mathrm{~cm}$ (Table 1 ). For effective generation of a meteotsunami, the atmospheric disturbance must propagate with a nearresonant speed: $U \sim c, F r \sim 1.0$. In that case, the ocean waves begin to actively accumulate energy from the atmosphere and amplify rapidly. Such resonantly amplified waves can then devastatingly impact the endangered coast. Due to the low-resolution sampling interval of the available air pressure measurements, and their total unavailability over Iran, our best attempt at guessing the speed of air pressure disturbances was to approximate it with a 500-hPa wind speed. In Fig. 14, we show the Froude number, defined as the ratio of the ERA-Interim wind and the phase speed of long ocean waves, at two ERA-Interim time periods (00:00 and 06:00 UTC on 19 March 2017) surrounding the tsunami event at $\sim$ 05:00 UTC. It appears that before the tsunami, there was a wide area in front of Dayyer with Froude number, $\mathrm{Fr} \sim 0.9$ to 1.1. Combined with the wind directed towards the Iranian coast, these are ideal conditions for meteotsunami generation, if the air pressure disturbance is strong enough. It is also indicative that the Froude number for the southern coast of the PG was far from unity, and in this region the governing upper-level winds were directed along the coast. Therefore, atmospheric pressure disturbances propagating over the southern coast of the PG (Kuwait, Saudi Arabia, Bahrain, Qatar, UAE, and Oman), could intensify high-frequency sea level oscillations, but could not produce really hazardous waves. The only area where such waves could be formed was the Dayyer region, i.e. exactly the region where the tsunami occurred. The available tide gauge data along the eastern and southern coasts of the PG (Table 1; Fig. 4) support this conclusion: the high frequency sea level activity was recorded at the corresponding locations exactly at the arrival times of the air pressure disturbances, but only in the area of Dayyer were the oscillations of extreme height. 

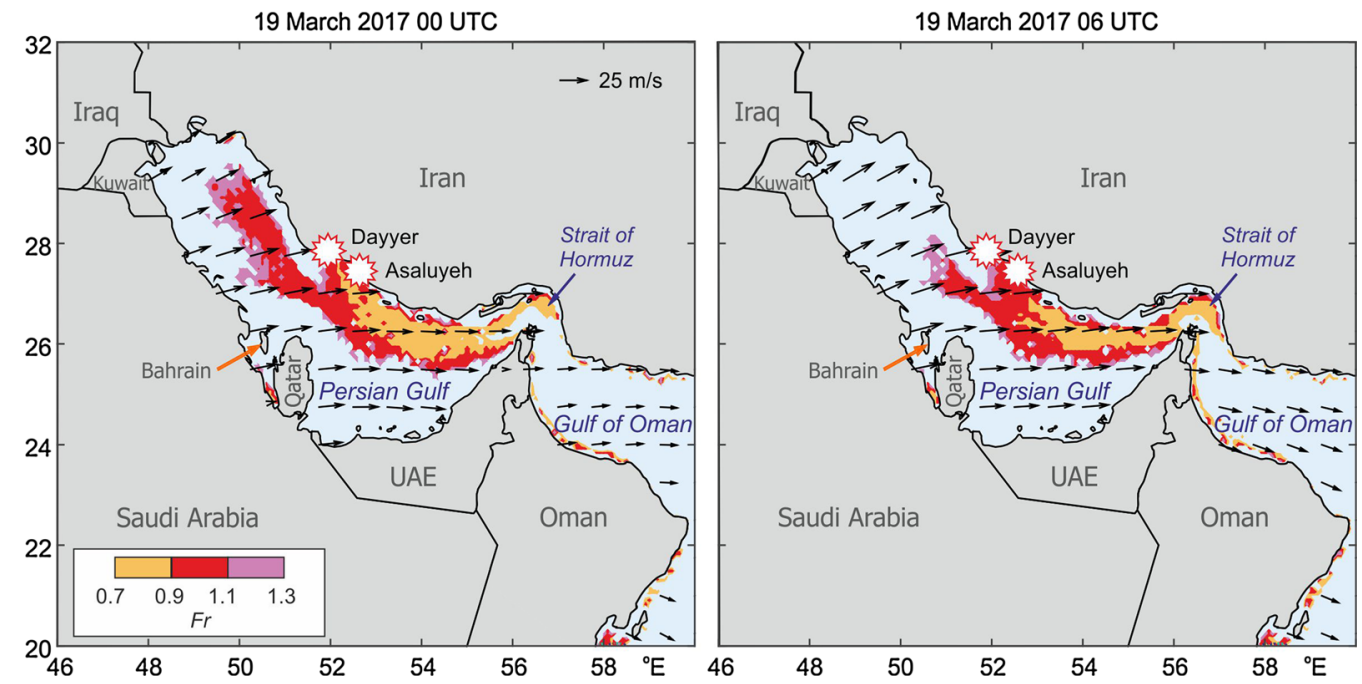

Figure 14

The region of the Persian Gulf with meteotsunami-favourable areas of $0.7<F r<1.3$, where $F r$ is the Froude number, defined as the ratio of the wind speed at a height of $500 \mathrm{hPa}$ and the phase speed of long ocean waves. a At 00:00 UTC and b at 06:00 UTC on 19 March 2017. Multibeam white stars indicate the locations of the highest measured meteotsunami waves; 500-hPa wind vectors are superimposed over the sea

\section{Discussions}

Our understanding of meteotsunamis-destructive atmospherically generated tsunami-like waves and associated hazards-has considerably advanced during the last 15 years (Monserrat et al. 2006; Rabinovich et al. 2009; Bailey et al. 2014; Šepić et al. 2015, 2018a, b; Horvath et al. 2018). The phenomenon has been reported and investigated throughout the entire World Ocean (Pattiaratchi and Wijeratne 2015; Vilibić et al. 2016). There are several "hot spots" around the world, where strong meteotsunamis occur regularly, such as Ciutadella Harbour in Spain, Vela Luka and Stari Grad harbours in Croatia, Nagasaki and Makurazaki bays in Japan. The hazardous meteotsunami events at these places are known, expected and theoretically can be forecast. In fact, preliminary meteotsunami warning systems have already been created in certain affected countries, in particular, in Spain (Marcos et al. 2009; Renault et al. 2011) and Croatia (Vilibić et al. 2016). Such systems are under development in some other countries, e.g. in USA, Portugal and Japan.

The difficult thing about the Dayyer event of 19 March 2017 is that it occurred in a place where such tsunami-like waves had never been reported before.
Therefore, a question arises: Is this place also a "hot spot", where similar events took place in the past, but remained unnoticed, or was the event totally accidental? The question is quite important and urgent. Our findings indicate that the main reasons for this catastrophic event were a specific combination of external factors, i.e. particular resonant parameters of atmospheric disturbances, propagating across the Persian Gulf, and internal factors, i.e. the local topography/depth distribution, favourable for the local resonance and strong amplification of incoming waves. Can such a situation repeat once again, or is the probability of such a coincidence negligible?

The best way to address this question is to collect and examine high-resolution sea levels at Dayyer and Asaluyeh. Have any extreme events been observed at these sites before? How strong were sea level oscillations recorded at these stations in the past? Unfortunately, the authors could not find such information. However, the absence of historical reports about tsunami-like destructive events in the PG, obviously indicates that the Dayyer meteotsunami of 19 March 2017 should be considered as a rare phenomenon for this region. At the same time, if such a destructive event occurred at this coast once, we may assume that sooner or later it will occur there again. 
As it follows from the results of the field survey of Salaree et al. (2018) and from our analysis of the tide gauge data, the Dayyer tsunami was a local event; it affected only a relatively short segment of the Iranian coast, roughly between Dayyer and Asaluyeh. The reason is explained in our Fig. 14; specifically, for the PG shelf adjacent to this coast the atmospheric disturbance speed, $U$, was close to the speed of long ocean waves, $c: U \sim c, F r \sim 1.0$. There were no other regions in the Persian Gulf where these conditions were satisfied and there were no other coastal areas where strong sea level oscillations were reported on 18-20 March 2017. The area of Fr $\sim 1$ was of $\sim 100 \mathrm{~km}$ width. If we assume that the atmospheric disturbance responsible for the Dayyer meteotsunamis had a speed of $\sim 26 \mathrm{~m} / \mathrm{s}$, and properties similar to that of the strongest disturbance (D6) recorded over the PG during 18-21 March (Table 2), i.e. height of $\sim 6 \mathrm{hPa}$ and rate of air pressure change up to $3.0 \mathrm{hPa} / 5 \mathrm{~min}$, and if we assume that its ocean wave period was $\sim 14 \mathrm{~min}$ (Fig. 6), we can estimate its wave length to be $\sim 22 \mathrm{~km}$. Then, following the numerical exercise by Vilibić (2008), we can estimate the height of long ocean waves generated by such an atmospheric disturbance at the end of the $100-\mathrm{km}$ path over which $\mathrm{Fr} \sim 1$, to be $\sim 70$ to $80 \mathrm{~cm}$. Over this path an ocean wave propagates as a forced wave locked to the atmospheric disturbance. Once the ocean wave leaves the area of $U \sim c, F r \sim 1$ and enters the shallower area of $U>c, F r>1$, it starts propagating as a free wave. However, due to the Greens law, its amplification continues all the way to the coast. The Green law states that (Lamb 1932):

$$
H_{2}=\sqrt[4]{\frac{d_{1}}{d_{2}}} H_{1}
$$

where $H_{1}$ and $H_{2}$ are wave heights of ocean waves at locations with corresponding water depths $d_{1}$ and $d_{2}$. Assuming that $d_{1}=70 \mathrm{~m}, \quad d_{2}=1 \mathrm{~m}, \quad$ and $H_{1}=80 \mathrm{~cm}$, it follows that $H_{2}=\sim 230 \mathrm{~cm}$, in good agreement with the maximum height of wave recorded in the region of Dayyer (Table 1). Additional amplification can be expected at the coast due to final shoaling and local bathymetry and topography characteristics. The question, however, remains: How common is this situation?
As was emphasized by Monserrat et al. (2006), a "classic" meteotsunami is a resonant phenomenon, mainly associated with the Proudman resonance, when $U \sim c$ (cf. Vilibić 2008). Monserrat and Thorpe $(1992,1996)$ indicated that tsunamigenic atmospheric disturbances have a typical speed $U \sim$ 20 to $30 \mathrm{~m} / \mathrm{s}$. This means that the resonant generation of meteotsunamis should occur in regions where long ocean waves have the same speed: $c \sim 20$ to $30 \mathrm{~m} / \mathrm{s}$. Figure 15 shows the distribution of $c=\sqrt{g h}$ in the Persian Gulf. It is seen that the "resonant region" is the northeastern part of the gulf adjacent to the Dayyer/Asaluyeh coast, which was destructively affected by the 2017 Dayyer tsunami. This means that it is not an accident that the 2017 event occurred in this particular region. Actually, the Dayyer/Asaluyeh coast may be considered as a "hot zone", which is potentially under risk of similar events that can impact this coast in the future.

Local meteotsunamis are normally produced by intense, but relatively small-scale and short-lived, tsunamigenic disturbances (Thomson et al. 2009). A number of such disturbances was recorded on 18-22 March 2017 in the PG region (Figs. 9, 10, 11). Unfortunately, the lack of high-resolution atmospheric measurements in the affected region did not allow us to identify the exact disturbance responsible

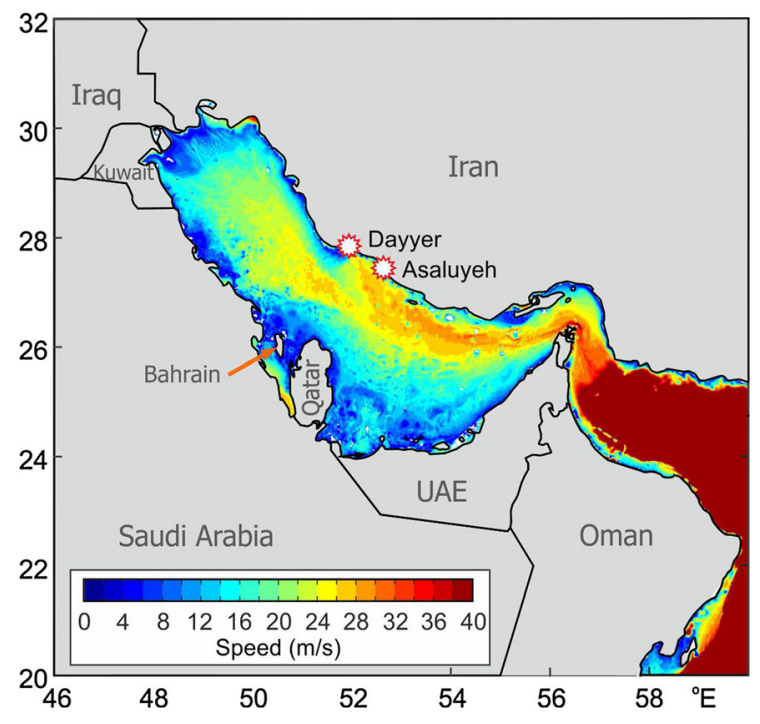

Figure 15

The distribution of long wave speed (colour map) according to Eq. (1) in the Persian Gulf region 
for the 2017 Dayyer tsunami and to estimate its characteristics. However, certain information about the forcing can be obtained based on analysis of tide gauge data. Stations Dayyer and Asaluyeh are located on the northeastern coast of the Persian Gulf, only $80 \mathrm{~km}$ from each other (Fig. 1). Nevertheless, the spectral ratios ("source functions") are noticeably different for the two stations (Fig. 6c, d). This means that either the extreme waves at these two stations were generated by two independent small-scale atmospheric disturbances (the results of Thomson et al. 2009 and Šepić et al. 2015 showed that typical sizes of such disturbances are a few tens of kilometres) or that the propagating disturbance had substantially different parameters in the cross-travel direction (the atmospheric systems during the event propagated in the northeastern direction, i.e. normal to the affected Iranian coast of the PG-see Sect. 5).

Šepić et al. (2015) indicated the generation of numerous intense, small-scale tsunamigenic atmospheric disturbances over the Mediterranean/Black Sea region on 23-27 June 2014 was associated with anomalous atmospheric conditions, including (1) inflow of warm and dry air from Africa; (2) a strong high-altitude jet stream; and (3) the presence of unstable atmospheric layers characterized by a small Richardson number, ${ }^{2} R i<0.25$. Values of the Richardson number smaller than 0.25 imply the presence of unstable atmospheric layers. From many points of view, the situation over the Persian Gulf on 18-22 June 2017 was very similar (see Sect. 5). Such atmospheric conditions look anomalous and rare, but they are not exceptional and can be forecast. Moreover, the weather in the $\mathrm{PG}$ region is generally moving from the western sector. This means that atmospheric disturbances will be first recorded at stations in Kuwait, Saudi Arabia, Bahrain and Qatar and only then at the Iranian coast of the Persian Gulf. The measurement of intense tsunamigenic air pressure disturbances at stations in these countries can be used as an indicator of possible extreme waves on the Dayyer/Asaluyeh coast.

\footnotetext{
${ }^{2}$ The Richardson number is a dimensionless parameter which expresses the ratio of the atmospheric buoyancy term to the flow shear term (vertical shear of horizontal wind speed).
}

A long list of damaging meteotsunami events observed recently in various regions of the world (Brazil, South Africa, Australia, Netherlands, USA, Chile, Japan, Republic of Korea, Bulgaria, UK, France, Portugal and Ukraine) demonstrates the substantial threat of this phenomenon for coastal regions. A devastating event at Dayyer, i.e. in a new region for meteotsunamis, requires a worldwide knowledge of this natural hazard. Despite multitudinous information on this phenomenon accumulated recently, meteotsunamis still present a challenge for researchers and emergency managers. Unlike tectonic tsunamis, which are preceded by major submarine earthquakes, meteotsunamis are hardly predictable and can be considered as silent and unexpected events. We showed that the Froude number (Eq. 2) is a useful index for identification of "hot spots" and forecasting possible meteotsunamis. We used this approach for the Dayyer meteotsunami of 19 March 2017 and results indicate the high perspective of this method. Based on this successful experience, we can recommend a similar approach for some other potentially risky regions of the world oceans. High-resolution monitoring of air pressure disturbances, satellite imaging of atmospheric processes, continuous inspection of the high-altitude jetstream regime, combined with estimation of the current Froude number for "hot-spot" regions, are probably the main directions for the meteotsunami warning and mitigation strategies in the future.

\section{Conclusions}

A destructive event occurred on 19 March 2017 on the northeastern coast of the Persian Gulf: the extreme tsunami-like waves with runup heights of $\sim 3 \mathrm{~m}$ strongly impacted the area of Dayyer (Iran) and caused five deaths, several tens of people injured, and severe damage. The thorough examination of this event provided by Salaree et al. (2018), excluded the possibility that these waves were produced by a seismic source or by an underwater landslide; consequently, the authors assumed the atmospheric origin of the event, that can be termed as a meteotsunami. To support this assumption, the authors of the present study used the data from 12 
tide gauges, located along the coasts of the Persian Gulf and the Gulf of Oman, and various meteorological information, including satellite images, highaltitude isohypse maps and 47 high-resolution air pressure recorders. The main findings of our study are the following:

- The Dayyer event of 19 March 2017 was a local event; maximum trough-to-crest wave heights of 197 and $234 \mathrm{~cm}$ were recorded at two near-field cities, Dayyer and Asaluyeh (both in Iran, $80 \mathrm{~km}$ from each other), respectively. At all other sites these heights were $<35 \mathrm{~cm}$.

- The observed wave periods were in the range of 10-40 min; the dominant wave periods were 15-20 min.

- No earthquakes or visible landslides were reported at the time of the event which indicates that the event was due to atmospheric processes and thus may be considered as a "meteorological tsunami". This conclusion is supported by various atmospheric and satellite data.

- Analysis of 47 air pressure records resulted in identification of 10 distinctive, potentially tsunamigenic, pressure disturbances in the PG region in the period 18-22 March 2017. The atmospheric conditions over the PG were found to be highly favourable for generation of meteotsunamis and very similar to those that caused a chain of strong meteotsunamis in the Mediterranean and Black Sea regions in 23-27 June 2014.

- Based on the 500-hPa wind speed, we estimated the propagation speed of the atmospheric disturbances to be in the range of $21-38 \mathrm{~m} / \mathrm{s}$; the wind speed and direction during the Dayyer event were $\sim 26 \mathrm{~m} / \mathrm{s}$ and $257^{\circ}$, respectively.

- The Froude number, Fr, estimated as the ratio of the speed of the air disturbance and the long wave speed, on 19 March 2017 was close to resonance, $\mathrm{Fr} \sim 0.9$ to 1.1 , specifically in the area of Dayyer/ Asaluyeh, which is the most favourable for meteotsunami generation.

In general, our findings indicate that the northeastern coast of the Persian Gulf should be considered as a "hot spot", highly vulnerable to extreme atmospherically induced tsunami-like waves. The atmospheric conditions of 18-22 March 2017 are anomalous, but they are not exceptional and can occur again in the future. However, taking into account the general eastward propagation direction of the atmospheric processes, we may assume that these tsunamigenic weather conditions can be forecast based on the information from stations in Kuwait, Saudi Arabia, Bahrain and Qatar, located to the west of the risky region.

\section{Acknowledgements}

Tide gauge data used in this study were provided by various agencies in the Persian Gulf region and international organisations: the Port and Maritime Organization (PSO) of Iran (https://www.pmo.ir/en/ home), the Hydrographic Unit of the Qatar Ministry of Municipality and Environment (http://www.mme. gov.qa), the National Cartographic Center (NCC) of Iran (http://www.ncc.org.ir), and the Intergovernmental Oceanographic Commission, UNESCO (http://www.ioc-sealevelmonitoring.org/). We are grateful to Mr Vladan Janković (Qatar Ministry of Municipality and Environment) for providing us the Qatar sea level data. Air pressure data are from the amateur meteorological network Wunderground (https://www.wunderground.com/wundermap). The satellite data were downloaded from the EUMETSAT Meteosat7 satellite (https://www.eumetsat.int/ website/home/Satellites/CurrentSatellites/Meteosat/ index.html). The authors gratefully acknowledge Richard Thomson and Fred Stephenson (both from the Institute of Ocean Sciences, Sidney, BC, Canada) for valuable comments and suggestions. $\mathrm{MH}$ is funded by the Brunel University London through the Brunel Research Initiative and Enterprise Fund 2017/18 (BUL BRIEF). The work for AR was partially supported by the Russian State Assignment of IO RAS \# 0149-2019-0005 and by the FCT-funded project FAST (PTDC/CTA-MET/32004/2017). The work of JS has been supported by the Croatian Science Foundation under the project MESSI (UKF Grant no. 25/15). This article benefited from constructive review comments from Emile A. Okal (Northwestern University, USA) and Rachid Omira (Instituto Português do Mar e da Atmosfera, Portugal) for which we are sincerely grateful. 


\section{Compliance with Ethical Standards}

Conflict of interest The authors declare that they have no competing interests regarding the work presented in this article.

Open Access This article is distributed under the terms of the Creative Commons Attribution 4.0 International License (http://creativecommons.org/licenses/by/4.0/), which permits unrestricted use, distribution, and reproduction in any medium, provided you give appropriate credit to the original author(s) and the source, provide a link to the Creative Commons license, and indicate if changes were made.

Publisher's Note Springer Nature remains neutral with regard to jurisdictional claims in published maps and institutional affiliations.

\section{REFERENCES}

Ambraseys, N. N. (2008). Descriptive catalogues of historical earthquakes in the Eastern Mediterranean and the Middle East. In J. Fréchet, M. Meghraoui, \& M. Stucchi (Eds.), Historical seismology. Modern approaches in solid earth sciences (Vol. 2, pp. 25-39). Dordrecht: Springer.

Bailey, K., DiVeglio, C., \& Welty, A. (2014). An examination of the June 2013 East Coast meteotsunami captured by NOAA observing systems. NOAA Techical Report NOS CO-OPS 079, p. 56.

Bechle, A. J., Kristovich, D. A. R., \& Chin, H. W. (2015). Meteotsunami occurrences and causes in Lake Michigan. Journal of Geophysical Research Oceans, 120, 8422-8438. https:// doi.org/10.1002/2015jc011317.

Belušić, D., Grisogono, B., \& Bencetić Klaić, Z. (2007). Atmospheric origin of the devastating coupled air-sea event in the east Adriatic. Journal of Geophysical Research Atmospheres, 112, D17111. https://doi.org/10.1029/2006jd008204.

Churchill, D. D., Houston, S. H., \& Bond, N. A. (1995). The Daytona Beach wave of 3-4 July 1992: A shallow water gravity wave forced by a propagating squall line. Bulletin of the American Meteorological Society, 76, 21-32.

El Sabh, M. I., \& Murty, T. S. (1989). Storm surges in the Arabian Gulf. Natural Hazards, 1, 371-385.

Ewing, M., Press, F., \& Donn, W. L. (1954). An explanation of the Lake Michigan wave of 26 June 1954. Science, 120, 684-686.

Fritz, H. M., Blount, C. D., Albusaidi, F. B., \& Al-Harthy, A. H. M. (2010). Cyclone Gonu storm surge in Oman. Estuarine Coastal and Shelf Science, 86(1), 102-106.

Greenspan, H. P. (1956). The generation of edge waves by moving pressure distributions. Journal of Fluid Mechanics, 1, 574-592.

Heidarzadeh, M., Necmioglu, O., Ishibe, T., \& Yalçiner, A. C. (2017). Bodrum-Kos (Turkey-Greece) Mw 6.6 earthquake and tsunami of 20 July 2017: A test for the Mediterranean tsunami warning system. Geoscience Letters, 4, 31. https://doi.org/10. 1186/s40562-017-0097-0.

Heidarzadeh, M., Pirooz, M. D., Zaker, N. H., Yalçiner, A. C., Mokhtari, M., \& Esmaeily, A. (2008). Historical tsunami in the Makran Subduction Zone off the southern coasts of Iran and
Pakistan and results of numerical modeling. Ocean Engineering, 35(8), 774-786.

Heidarzadeh, M., Satake, K., Murotani, S., Gusman, A. R., \& Watada, S. (2015). Deep-water characteristics of the trans-Pacific tsunami from the 1 April $2014 M_{\mathrm{w}} 8.2$ Iquique, Chile Earthquake. Pure and Applied Geophysics, 172(3), 719-730.

Hibiya, T., \& Kajiura, K. (1982). Origin of the 'Abiki' phenomenon (a kind of seiche) in Nagasaki Bay. Journal of the Oceanographical Society of Japan, 38, 172-182.

Holton, J. R. (2004). An introduction to dynamic meteorology (p. 528). New York: Elsevier Academic Press.

Honda, K., Terada, T., Yoshida, Y., \& Isitani, D. (1908), An investigation on the secondary undulations of oceanic tides. Journal of the College of Science, Imperial University of Tokyo, p. 108.

Horvath, K., Šepić, J., \& Prtenjak, M. T. (2018). Atmospheric forcing conducive for the Adriatic 25 June 2014 Meteotsunami event. Pure and Applied Geophysics, 175(11), 3817-3837.

Jansà, A., Monserrat, S., \& Gomis, D. (2007). The rissaga of 15 June 2006 in Ciutadella (Menorca), a meteorological tsunami. Advances in Geosciences, 12, 1-4.

Kerkmann, J. (2005). Applications of METEOSAT second generation (MSG)—RGB images: Part 04, RGB composites with channels 01-11 and their interpretation, EUMETSAT. http:// oiswww.eumetsat.org/WEBOPS/msg_interpretation/msg_chann els.php.

Lamb, H. (1932). Hydrodynamics (6th ed., p. 768). Cambridge: Cambridge University Press.

Ličer, M., Mourre, B., Troupin, C., Krietemeyer, A., Jansà, A., \& Tintoré, J. (2017). Numerical study of Balearic meteotsunami generation and propagation under synthetic gravity wave forcing. Ocean Modelling, 111, 38-45.

Lin, N., \& Emanuel, K. (2016). Grey swan tropical cyclones. Nature Climate Change, 6(1), 106-111.

Marcos, M., Monserrat, S., Medina, R., Orfila, A., \& Olabarrieta, M. (2009). External forcing of meteorological tsunamis at the coasts of the Balearic Islands. Physics and Chemistry of the Earth, 34, 938-947.

Monserrat, S., Rabinovich, A. B., \& Casas, B. (1998). On the reconstruction of the transfer function for atmospherically generated seiches. Geophysical Research Letters, 25, 2197-2200.

Monserrat, S., \& Thorpe, A. J. (1992). Gravity-wave observations using an array of microbarographs in the Balearic Islands. Quarterly Journal of the Royal Meteorological Society, 118, 259-282.

Monserrat, S., \& Thorpe, A. J. (1996). Use of ducting theory in an observed case of gravity waves. Journal of the Amtospheric Sciences, 53(12), 1724-1736.

Monserrat, S., Vilibić, I., \& Rabinovich, A. B. (2006). Meteotsunamis: Atmospherically induced destructive ocean waves in the tsunami frequency band. Natural Hazards and Earth System Sciences, 6, 1035-1051.

Munk, W. H., Snodgrass, F. E., \& Carrier, G. F. (1956). Edge waves on the continental shelf. Science, 123(3187), 127-132.

Olabarrieta, M., Valle-Levinson, A., Martinez, C. J., Pattiaratchi, C., \& Shi, L. (2017). Meteotsunamis in the northeastern Gulf of Mexico and their possible link to El Niño Southern Oscillation. Natural Hazards, 88, 1325-1346. https://doi.org/10.1007/ s11069-017-2922-3.

Orlić, M. (1980). About a possible occurrence of the Proudman resonance in the Adriatic. Thalassia Jugoslavica, 16(1), 79-88. 
Pasquet, S., \& Vilibić, I. (2013). Shelf edge reflection of atmospherically generated long ocean waves along the central US, East Coast. Continental Shelf Research, 66, 1-8.

Pattiaratchi, C. B., \& Wijeratne, E. M. S. (2015). Are meteotsunamis an underrated hazard? Philosophical Transactions of the Royal Society A, 373, 20140377.

Powers, J. G., \& Reed, R. J. (1993). Numerical simulation of the large-amplitude mesoscale gravity-wave event of 15 December 1987 in the central United States. Monthly Weather Review, 121, 2285-2308.

Proudman, J. (1929). The effects on the sea of changes in atmospheric pressure. Geophysical Supplements to the Monthly Notices of the Royal Astronomical Society, 2, 197-209.

Rabinovich, A. B. (1997). Spectral analysis of tsunami waves: Separation of source and topography effects. Journal of Geophysical Research, 102(C6), 12663-12676.

Rabinovich, A. B. (2009). Seiches and harbor oscillations. In Y. C. Kim (Ed.), Handbook of coastal and ocean engineering (Vol. 9, pp. 193-236). Singapore: World Scientific Publ.

Rabinovich, A. B., \& Monserrat, S. (1996). Meteorological tsunamis near the Balearic and Kuril Islands: Descriptive and statistical analysis. Natural Hazards, 13, 55-90.

Rabinovich, A. B., \& Thomson, R. E. (2007). The 26 December 2004 Sumatra tsunami: Analysis of tide gauge data from the World Ocean. Part 1: Indian Ocean and South Africa. Pure and Applied Geophysics, 164(2/3), 261-308.

Rabinovich, A. B., Thomson, R. E., \& Fine, I. V. (2013). The 2010 Chilean tsunami off the west coast of Canada and the northwest coast of the United States. Pure and Applied Geophysics, 170(9-10), 1529-1565. https://doi.org/10.1007/s00024-0120541-1.

Rabinovich, A. B., Vilibić, I., \& Tinti, S. (2009). Meteorological tsunamis: Atmospherically induced destructive ocean waves in the tsunami frequency band. Physics and Chemistry of the Earth, 17(34), 891-893.

Renault, L., Vizoso, G., Jansá, A., Wilkin, J., \& Tintoré, J. (2011). Toward the predictability of meteotsunamis in the Balearic Sea using regional nested atmosphere and ocean models. Geophysical Research Letters, 38, L10601. https://doi.org/10.1029/ 2011 g1047361.

Salaree, A., Mansouri, R., \& Okal, E. A. (2018). The intriguing tsunami of 19 March 2017 at Bandar Dayyer, Iran: Field survey and simulations. Natural Hazards, 90(3), 1277-1307.

Sallenger, A. H., List, J. H., Gelfenbaum, G., Stumpf, R. P., \& Hansen, M. (1995). Large wave at Daytona Beach, Florida, explained as a squall-line surge. Journal of Coastal Research, 11, 1383-1388.

Šepić, J., Međugorac, I., Janeković, I., Dunić, N., \& Vilibić, I. (2016). Multi-meteotsunami event in the Adriatic Sea generated by atmospheric disturbances of 25-26 June 2014. Pure and Applied Geophysics, 173, 4117-4138.

Šepić, J., Rabinovich, A. B., \& Sytov, V. N. (2018a). Odessa tsunami of 27 June 2014: Observations and numerical modelling. Pure and Applied Geophysics, 175(4), 1545-1572.

Šepić, J., Vilibić, I., \& Belušić, D. (2009). Source of the 2007 Ist meteotsunami (Adriatic Sea). Journal of Geophysical Research, 114, C03016. https://doi.org/10.1029/2008jc005092.

Šepić, J., Vilibić, I., Rabinovich, A. B., \& Monserrat, S. (2015). Widespread tsunami-like waves of 23-27 June in the Mediterranean and Black Seas generated by high-altitude atmospheric forcing. Scientific Reports, 5(11682), 1-5. https://doi.org/10. 1038/srep11682.

Šepić, J., Vilibić, I., Rabinovich, A., \& Tinti, S. (2018b). Meteotsunami ("Marrobbio") of 25-26 June 2014 on the Southwestern Coast of Sicily, Italy. Pure and Applied Geophysics, 175(4), 1573-1593.

Soloviev, S. L. (1978). Tsunamis. The assessment and mitigation of earthquake risk (Natural Hazard, 1) (pp. 118-139). Paris: UNESCO.

Tanaka, K. (2010). Atmospheric pressure-wave bands around a cold front resulted in a meteotsunami in the East China Sea in February 2009. Natural Hazards and Earth System Sciences, 10, 2599-2610.

Thomson, R. E., \& Emery, W. J. (2014). Data analysis methods in physical oceanography (3rd ed., p. 728p). New York: Elsevier Science.

Thomson, R. E., Rabinovich, A. B., Fine, I. V., et al. (2009). Meteorological tsunamis on the coasts of the British Columbia and Washington. Physics and Chemistry of the Earth, 34, 971-988.

Vilibić, I. (2008). Numerical simulations of the Proudman resonance. Continental Shelf Research, 28, 574-581.

Vilibić, I., Šepić, J., Rabinovich, A. B., \& Monserrat, S. (2016). Modern approaches in meteotsunami research and early warning. Frontiers in Marine Science, 3(57), 1-7. https://doi.org/10.3389/ fmars.2016.00057.

Wang, S., \& Zhang, F. (2007). Sensitivity of the mesoscale gravity waves to the baroclinity of jet-front systems. Monthly Weather Review, 135, 670-688.

Wertman, C. A., Yablonsky, R. M., Shen, Y., Merrill, J., Kincaid, C. R., \& Pockalny, R. A. (2014). Mesoscale convective system surface pressure anomalies responsible for meteotsunamis along the US East Coast on June 13th, 2013. Scientific Reports, 4, 7143. https://doi.org/10.1038/srep07143.

Zaytsev, O., Rabinovich, A. B., \& Thomson, R. E. (2017). The 2011 Tohoku tsunami on the coast of Mexico: A case study. Pure and Applied Geophysics, 174(8), 2961-2986. https://doi.org/10. 1007/s00024-017-1593-z. 